\title{
Antiarrhythmic Versus Antifibrillatory Actions: Inference from Experimental Studies
}

\author{
Benedict R. Lucchesi, PhD, MD, Liguo Chi, MD, Gregory S. Friedrichs, PhD, \\ Shawn C. Black, PhD, and Andrew C. G. Uprichard, MD
}

Pathophysiology of the coronary circulation is a major contributor to altering the myocardlal substrate, rendering the heart susceptible to the onset of arrhythmias associated with sudden cardiac death. Antiarrhythmic drug therapy for the prevention of sudden cardiac death has been provided primarily on the basis of trial and error and in some instances based on ill-sulted preclinical evaluations. The findings of the Cardlac Arrhythmia Suppression Trial (CAST) requires a reexamination of the manner in which antiarrhythmic drugs are developed before entering into clinical testing. The major deficiency in this area of experimental investigation has been the lack of animal models that would permit preclinical studies to identify potentially useful or deleterlous therapeutic agents. Further, CAST has emphasized the need to distinguish between pharmacologic interventions that suppresses nonlethal disturbances of cardiac rhythm as opposed to those agents capable of preventing lethal ventricular tachycardia or ventricular fibrillation. Preclinical models for the testing of antifibrillatory agents must consider the fact that the superimposition of transient ischemic events on an underlying pathophysiologic substrate makes the heart susceptible to lethal arrhythmias. Proarrhythmic events, not observed in the normal heart, may become manifest only when the myocardial substrate has been altered. We describe a model of sudden cardlac death that may more closely simulate the clinical state in humans who are at risk. The experimental results show a good correlation with clinical data regarding agents known to reduce the incidence of lethal arrhythmias as well as those showing proarhythmic actions.

(Am J Cardiol 1993;72:25F-44F)

From the Department of Pharmacology, The University of Michigan Medical School, Ann Arbor, Michigan. Published investigations cited from this laboratory were supported by the National Institutes of Health, the Heart, Lung, and Blood Institute grant HL05806-33.

Address for reprints: Benedict R. Lucchesi, PhD, MD, Department of Pharmacology, 6322 Medical Science I, University of Michigan Medical School, Ann Arbor, Michigan 48109-0626.
A major cause of mortality in the United States as well as in other parts of the industrialized world is attributed to sudden cardiac death, a phenomenon most likely to occur in the diseased heart as a result of altered electrophysiology. "Sudden cardiac death" generally denotes death that is nonviolent, unexpected, witnessed, and instantaneous or occurs within a few minutes of an abrupt change in the previous clinical state. ${ }^{1}$ Despite a decrease in the number of sudden cardiac deaths over the past 20 years, the number of fatalities in the United States exceeds 300,000 per year. Approximately $60 \%$ of the fatal events occur in individuals without any previous diagnosis of heart disease. ${ }^{2}$ Clearly, sudden cardiac death is a major health issue of our times, accounting for $50 \%$ of all cardiovascular deaths, ${ }^{3}$ and the problem is compounded by the recent realization that not only has pharmacologic management done little to improve the situation, it may have contributed to the onset of the fatal events in susceptible individuals. ${ }^{4}$ The extent of the problem has made sudden cardiac death one of the most pressing unresolved clinical and public health concerns.

In most instances of sudden cardiac death, the underlying pathophysiology of the coronary artery circulation renders the heart susceptible to the onset and maintenance of a lethal dysrhythmia. That the "triggering" event is of a transient nature is suggested by the fact that patients resuscitated after sudden coronary death arc capable of maintaining a stable cardiac rhythm and, in many instances, do not display signs and symptoms suggestive of permanent myocardial injury. It is of fundamental importance, therefore, to understand what possible electrophysiologic factor (or factors) results in the transition from a stable activation sequence of the ventricular myocardium to one with multiple asynchronous circuits culminating in ventricular fibrillation. It is equally important to know what morphologic and electrophysiologic changes characterize the portion of the myocardium that is capable of serving as a suitable substrate for the triggering event that proceeds to ventricular fibrillation. 
The ischemically injured heart shows marked heterogeneity with respect to regional coronary artery blood flow to areas subserved by stenosed vessels. Further, ion fluxes, availability of substrate, and the superimposition of neural influences are capable of exerting deleterious effects, which render the heart more susceptible to the triggering event leading to the onset of ventricular fibrillation.

Sudden cardiac death may be considered to involve an interaction between structural derangements of the heart, transient functional disturbances, and the spccific clectrophysiologic events responsible for the fatal arrhythmia. ${ }^{3}$ Coronary atherosclerosis and its associated influences on the heart constitutes the major pathologic finding in the vast majority of persons who succumb to sudden cardiac death. Patients who have experienced a major cardiovascular event are at high risk of sudden cardiac death during the first 6-18 months after the index event, suggesting a time dependence of risk and indicating the need for appropriate therapy in the early period. ${ }^{5}$

\section{THE PREFIBRILATORY STATE}

Understanding the factors that characterize the prefibrillatory state as targets for drug Intervention: The role of drug intervention in the prevention of sudden death is based on the premise of there being treatable factors that can be identified in those at risk. One factor, recognized for many years, is the finding of chronic ventricular ectopy in patients after myocardial infarction. ${ }^{6-11}$ The assumption was made that premature ventricular complexes appearing in the vulnerable phase of myocardial repolarization were responsible for the initiation of malignant arrhythmias in these individuals. Therefore, it seemed entirely appropriate that an agent capable of suppressing premature ventricular complexes would be effective in preventing sudden death. Indeed, early studies with lidocaine, an effective agent in suppressing ectopy, ${ }^{12}$ suggested that its use might be associated with a decreased incidence of ventricular fibrillation. ${ }^{13}$ After this, however, there appeared a number of reports using several agents that failed to substantiate this claim and, when reviewed in early metaanalysis, appeared to suggest an adverse trend. ${ }^{14,15}$ Nevertheless, the analyses were not without criticism for dissimilarities in study designs and populations, so it was not until the advent of the Cardiac Arrhythmia Suppression Trial (CAST) that the prescribing public was given a clear picture of the issue. CAST was designed specifically to address the question of whether premature ventricular complex suppression was an appropriate surrogate for mortality in the postmyocardial infarction population. Encainide, flecainide, and moricizine were identified in the Cardiac Arrhythmia Pilot Study (CAPS) $)^{16}$ as "premature ventricular complex killers" and were considered to be the agents of choice for CAST. Despite (ironical) concern over the ethics of a placebo arm, it was included in the major multicenter study, which employed an elegant dose titration in a double-blind manner. Preliminary (CAST I) and final (CAST II) results from this study provided the definitive answer that the use of all 3 agents was associated with significant increases in arrhythmic deaths. ${ }^{17,18}$ Further, the adverse trends were apparent in all identified subgroups and, in view of the diverging curves, were thought to be ongoing throughout the trial.

An alternative clinical model for the testing of antiarrhythmic drugs is the unmasking of malignant recntrant arrhythmias by electrophysiologic testing. An appropriately timed stimulus, delivered through an in-dwelling cardiac cathctcr, can induce ventricular tachyarrhythmias in patients at risk of life-threatening disturbances in cardiac rhythm. ${ }^{19}$ Further, the same arrhythmias may be prevented by the use of individualized drug therapy. ${ }^{20,21}$ The induction of sustained ventricular arrhythmia is considered an objective endpoint by which to evaluate candidates for antiarrhythmic drug therapy. The rate at which inducible ventricular arrhythmias are suppressed during serial antiarrhythmic drug testing in survivors of sudden cardiac death is in the range of $20-50 \% .^{20,22,23}$ However, even when ventricular fibrillation is induced by programmed electrical stimulation in the electrophysiology laboratory, one cannot be sure that the substrate of the arrhythmia thus generated is identical to that pertaining at the time of sudden death, or that pharmacologic prevention of stimulus-induced ventricular fibrillation reflects protection against sudden death. The question remains, therefore, whether it is the fact that a patient's arrhythmia can be suppressed that is important, or if it is due to the associated drug therapy; in other words, is suppressibility per se associated with a good prognosis? To answer this would require a placebo-controlled trial in which patients with suppressible arrhythmias were compared with patients whose arrhythmias could not be prevented, but before embarking on this we must first be assured that electrophysiologic testing is an appropriate surrogate for mortality. The only study to date that addresses this question is the National 
Institutes of Health-sponsored Electrophysiology Study Versus Electrocardiographic Monitoring (ESVEM) trial. ${ }^{24}$ ESVEM uses mortality in determining the relative usefulness of electrophysiologic testing and Holter monitoring in assessing several antiarrhythmic agents, including quinidine, procainamide, mexiletine, propafenone, sotalol, and pirmenol (a class IA agent no longer being developed). An imipramine group was removed shortly after the trial was initiated. Until this trial reports in 1993, electrophysiologic testing cannot be recommended for routine use.

To summarize the clinical situation, therefore, whereas certain drugs (e.g., lidocaine, bretylium, amiodarone, and most recently, sotalol) do have the indication for prevention of recurrent ventricular fibrillation, no pharmacologic intervention has yet been shown to decrease the incidence of sudden cardiac death. Further, there appears to be no relevant surrogate endpoint for the evaluation of potential new therapies. The results of CAST have demonstrated that clinical testing of antiarrhythmic drugs cannot rely on a drug's ability to reduce the frequency and/or complexity of ventricular premature depolarizations. Even the application of more elaborate procedures, such as electrophysiologic testing for the evaluation of a drug's antiarrhythmic efficacy, may be misleading with respect to its efficacy in preventing the development of ventricular fibrillation. As long as the endpoint remains anything other than sudden cardiac death, any clinical trial or clinical use of a drug in patients determined to be at high risk will be carried out mostly on an empirical basis. An essential component in approaching the development of effective therapeutic interventions for the prevention of sudden cardiac death must include appropriate animal models for early preclinical testing, based on an understanding of the pathophysiologic milieu pertaining at the time of sudden death. At present, the approach to identifying therapeutic interventions for prevention of lethal arrhythmias is predicated on a drug's ability to alter various characteristics of the membrane action potential of cardiac tissues, alterations in ion channel function, or examination of the drug's ability to prevent or terminate one or more experimentally induced dysrhythmias. Unfortunately, few of the experimental approaches have a close relation to several important questions: First, can the agent under study prevent ventricular fibrillation? Second, can it serve as a candidate drug for a highly focused clinical trial in well-characterized subsets of patients who possess identifiable specific etio- logic features placing them at risk of succumbing to sudden cardiac death? Lastly, does the therapeutic agent of interest confer an antifibrillatory action under conditions in which the altered substrate (damaged myocardium) is subjected to transient ischemic events? The latter is of primary importance, since a drug capable of preventing or suppressing spontaneous or electrophysiologically induced reentrant rhythms in the nonischemic myocardium may be proarrhythmic or profibrillatory under conditions in which transient ischemic episodes are superimposed on a vulnerable substrate.

\section{THE MYOCARDLAL SUBSTRATE}

The essential substrate for reentrant rhythms and ventricular fibrillation: Postmortem studies indicate that in the majority of cases, ventricular fibrillation is a primary event and not related to acute myocardial infarction. ${ }^{25,26}$ Sudden cardiac death is known to occur most commonly in patients with previous myocardial ischemic injury secondary to advanced coronary artery atherosclerosis. ${ }^{27-29}$ Further, the finding in many cases of intracoronary thrombus without acute infarction suggests that ischemia, per se, may be acting as the trigger for the genesis of ventricular fibrillation in a vulnerable, electrically unstable ventricular myocardium. The electrophysiologic properties of ischemic myocardium, such as increased excitability, shortening of the ventricular refractory period, slowing of conduction velocity, and increased inhomogeneity in recovery may provide the milieu for the emergence of reentrant rhythms in a heart critically deranged by previous infarction. The concept of ischemia in a region remote from the infarct-related artery acting as the trigger for fatal ventricular arrhythmias was addressed by Schuster and Bulkley. ${ }^{30}$ In a study of 2 groups of patients with early postinfarction angina, they found that patients with remote ischemia constituted a group of hemodynamically stable patients who faced an unexpectedly high mortality compared with those patients whose angina arose from the peri-infarcted region. Schwartz and coworkers ${ }^{31,32}$ reproduced this phenomenon experimentally when they demonstrated a high incidence of ventricular fibrillation in a chronic canine model of myocardial infarction in which additional ischemia was initiated using a hydraulic coronary artcry occluder. Also using a canine model, Kabell and coworkers ${ }^{33}$ demonstrated a diminution in infarct collateral blood flow with distant ischemia. Since this was preceded by delayed epicardial activity within the 
area of preexisting infarction, it suggested that ischemia might be influencing the substrate of an infarcted area of myocardium to render it more suitable for the emergence of lethal arrhythmias.

Coronary vasospasm has been considered as a triggering mechanism for sudden death, especially since patients with atypical angina have demonstrated serious ventricular arrhythmias during episodes of spasm. ${ }^{34}$ Although the majority of survivors of cardiac arrest give no previous or subsequent history of atypical angina, in one study sudden death was observed in $17 \%$ of 114 patients with coronary vasospasm followed for a mean of 24 months. ${ }^{35}$

The concept that spasm may be an important contributor to sudden cardiac death is supported by data showing the relation between the diseasefree wall of the coronary artery and the severity of obstruction. $^{36,37}$ The mean disease-free wall arc length measured $17-23 \%$ of the total vessel circumference in eccentric coronary lesions that obstructed $50-90 \%$ of the cross-sectional area of the lumen. The ratio persisted regardless of the location of the lesion within the vessel. The normal arc may be capable of responding to vasospastic stimuli, as opposed to atheromatous material occupying the bulk of the arc, which appears firm and unlikely to change configuration in response to humoral or neurogenic stimuli. The potential exists for the dynamic alterations in coronary luminal dimensions most likely to occur along the disease-free circumference of the coronary artery. Thus, a clinically silent atherosclerotic lesion could be converted to a clinically symptomatic and possibly lethal lesion by additional spasm in the plaque-free segment of the vessel. Postmortem examination of human coronary artery segments has led to the suggestion that the atherosclerotic process leads to a decrease in density or sensitivity of the $\beta$ adrenoceptors in the smooth muscle of the coronary artcrics. ${ }^{38}$ The conclusion was that the intrinsic properties of human coronary smooth muscle may be one of the mechanisms of coronary spasm. There are no unequivocal markers at the time of necropsy to demonstrate that coronary artery spasm preceded the fatal arrhythmia. However, a distinctive finding in smooth muscle of coronary arteries suggestive of antemortem spasm has been reported in which "hypercontraction" of smooth muscle cells may give rise to dense eosinophilic bands, similar to those seen in reperfused cardiac muscle. ${ }^{39}$ Coronary artery contraction bands were found in $75 \%$ of the cases examined and were more com- mon in vessels with $<50 \%$ cross-sectional area obstruction than vessels with $>50 \%$ obstruction.

Another mechanism to be considered in the genesis of lethal arrhythmias is the role of the autonomic nervous system. Alterations in autonomic tone are well recognized in acute myocardial ischemia and may be inherently arrhythmogenic by nature of the increase in myocardial oxygen consumption and alterations in refractoriness. Inhomogenous adrenergic stimulation has been shown to precipitate arrhythmias in a number of animal models, ${ }^{40}$ whereas others have demonstrated a possible role of the sympathetic nervous system when acute ischemia is produced in the setting of previous myocardial infarction. ${ }^{31,32,41}$ Specifically, sympathetic hyperactivity favors the onset of lifethreatening cardiac arrhythmias, whereas vagal activation exerts a protective and antifibrillatory effect. ${ }^{41}$ Direct neural recording of vagal activity to the heart confirmed that vigorous reflex vagal activation during acute myocardial ischemia is associated with protection from ventricular fibrillation. ${ }^{42}$ Other factors contributing to the precipitating trigger in sudden death include those biochemical alterations (such as hypokalemia and hypomagnesemia) that are known to precipitate fatal arrhythmias in individuals at risk. Thus, a variety of factors may predispose the individual at risk to the development of lethal ventricular arrhythmias (Figure 1). Pathophysiologically, sudden cardiac death involves an interaction between structural abnormalities of the heart, transient functional disturbances, and the specific electrophysiologic events responsible for fatal arrhythmias.

\section{ISCHEMLA MUST BE DIFFERENTLATED FROM INFARCTION}

There is a period of healing after myocardial infarction in which the necrotic mass of tissue is converted to a dense, fibrous scar. The healed phase of myocardial infarction is characterized by a chronic alteration in myocardial structure that, in itself, is electrically stable. However, the structural abnormality is capable of influencing electrophysiologic parameters when other events are superimposed on the heart. In contrast, ischemia is a transient event due to an absolute or relative reduction in regional myocardial blood flow. The influence of ischemia on a structurally normal heart has a more favorable outcome compared with an ischemic event superimposed on a heart previously subjected to myocardial infarction. There is compelling evidence to indicate that regional myocardial ischemia superimposed on the previ- 
ously damaged heart, in contrast to a normal heart, is more likely to precipitate malignant and potentially lethal ventricular arrhythmia. ${ }^{43-45}$ Superimposition of an acute nonocclusive thrombus, an imbalance between oxygen supply and demand, metabolic or electrolyte changes, or neurophysiologic influences may establish the conditions necessary to sustain a reentrant rhythm leading to a lethal arrhythmia. Enhanced coronary artery vasomotor activity abruptly decreasing myocardial blood flow in a region remote from a region of previous myocardial infarction may precipitate symptoms of angina, disturbances in rhythm, and sudden cardiac death. ${ }^{35,46}$ Platelet aggregation at sites of coronary vessel damage and the release of vasoactive mediators have been implicated as major contributors to the initiation of lethal cardiac arrhythmias. ${ }^{47-50}$

\section{PRECUNICAL ASSESSMENT}

Antifibrillatory drug efficacy, using relevant experimental models: It is not our intent to discuss the pros and cons concerning the multitude of experimental models used for the study of antiarrhythmic drugs. Table I presents a listing of some of the more commonly used experimental models. The subject has been reviewed in detail in previous publications. ${ }^{51-54}$ Whole animal models for the evaluation of antiarrhythmic activity have relied on arrhythmias induced by cardiotoxic agents, electrical stimuli, or arrhythmias associated with coronary artery occlusion, with or without reperfusion. ${ }^{53}$ Other approaches include arrhythmias induced by catecholamines ${ }^{55}$ or electrical stimuli ${ }^{56,57}$ in the subacute phase of myocardial infarction. Although each of these techniques is capable of

\begin{tabular}{l} 
TABLE I Methods for Preclinical Evaluation of Antiarrhythmic \\
Agents \\
\hline Chemically induced arrhythmias \\
Aconitine \\
Hydrocarbon-catecholamine \\
Barium chloride \\
Digitalis glycosides \\
Potassium channel openers \\
Elcctrically induced arrhythmias \\
Ventricular fibrillation/defibrillation threshold \\
Repetitive ventricular response \\
Programmed electrical stimulation \\
Neurally induced arrhythmias \\
Application of stimuli to the lateral ventricle of the brain \\
Electrical stimulation of the autonomic nervous system \\
Emotional- or exercise-induced stress \\
Ischemia induced arrhythmias \\
Acute interruption of regional coronary artery blood flow (Harris 1 or 2 \\
stage) \\
Acute interruption of regional coronary artery blood flow followed by \\
reperfusion \\
Acute regional ischemia superimposed on a previously infarcted myo- \\
cardium
\end{tabular}

generating reliable and reproducible arrhythmias, they fail to provide an opportunity to examine the electrophysiologic environment at the time of ventricular fibrillation, or to study pharmacologic interventions aimed at preventing sudden cardiac death. The preclinical development of antiarrhythmic agents should emphasize the importance of designing animal models to address ventricular fibrillation, since it may represent one of the primary rhythm disturbances associated with sudden cardiac death, particularly in the heart altered by the presence of coronary artery disease. In light of the CAST results, ${ }^{17}$ animal models that evaluate a drug's capacity to reduce the number of innocent
FICURE 1. Dląram Illustrating the potential "insults" capable of contributing to the emergence of fatal ventilcular arrhythmlas in a heart criticalihy deranged from prevlous myocardial infarction. The use of programmed electrical stimulation in the postinfarction period is capable of unmasking the electrical instability, whlch is ultimately responslble for the terminal anthythmia. $(A D P=$ adenosine diphosphate)

\begin{tabular}{|c|c|}
\hline $\begin{array}{l}\text { SUPERIMPOSED INSULTS } \\
\text { TRANSIENT MYoCARDIAL ISCHEMIA } \\
\text { Platelet Aggregates } \\
\text { Serotonin, Thromboxane, ADP } \\
\text { Increased Coronary Artery Tone/Spasm } \\
\text { Endothelial Cell Dysfunction } \\
\text { Altered Autonomic Nervous System Activity } \\
\text { Neurotransmitter Release, Receptors } \\
\text { Altered Regional Myocardial Blood Flow } \\
\text { Central Nervous System Influences } \\
\text { Increased Myocardial Oxygen Demand }\end{array}$ & $\begin{array}{l}\text { SUBSTRATE } \\
\text { MYOCARDIAL INFARCTION } \\
\text { Acute } \\
\text { Healed } \\
\text { MYOCARDIAL HYPERTROPHY } \\
\text { CONGESTIVE HEART FAILURE } \\
\text { CARDIOMYOPATHY }\end{array}$ \\
\hline $\begin{array}{l}\text { EXOGENOUS INFLUENCES } \\
\text { Proarrhythmic Agents } \\
\text { Electrolyte Abmormalities } \\
\text { Hypoxemia, Acidosis }\end{array}$ & $\begin{array}{l}\text { PROGRAMMED } \\
\text { ELECTRICAL } \\
\text { STIMULATION }\end{array}$ \\
\hline ( о & $\begin{array}{l}\text { SPONTANEOUS OR INDUCED } \\
\text { ELECTRICAL INSTABILITY } \\
\text { Premature Ventricular Complexes } \\
\text { Ventricular Tachycardia } \\
\text { Torsades de Pointes }\end{array}$ \\
\hline
\end{tabular}




\begin{tabular}{|c|c|c|}
\hline Features & Inducible & Noninducible \\
\hline $\begin{array}{l}\text { Anterior infarct size } \\
\quad(\% \text { left ventricular mass) }\end{array}$ & $24.7 \pm 1.7$ & $5.3 \pm 1.1^{*}$ \\
\hline Time to ischemia (min) & $196 \pm 39$ & $225 \pm 30$ \\
\hline Sudden VF ( $<1$ hour) & $11 / 15$ & $2 / 15$ \\
\hline Delayed VF ( $<24$ hours) & $3 / 15$ & $0 / 15$ \\
\hline Thrombus mass (mg) & $7.2 \pm 1.81$ & $11.2 \pm 2.3$ \\
\hline Posterolateral infarct mass & $19.0 \pm 1.0(n=3)$ & $16.7 \pm 2.3(n=13)$ \\
\hline \multicolumn{3}{|l|}{$\begin{array}{l}{ }^{*} \mathrm{p}<0.001 . \\
\text { VF: Ventricular fibrillation. } \\
\text { Summarized from Wilber et al. } 58\end{array}$} \\
\hline
\end{tabular}

ventricular premature depolarizations may be of limited value in new drug development. The ideal drug may be one that is effective against sustained ventricular tachycardia/fibrillation that occurs "spontaneously" in the presence of previous myocardial injury. There may be a clear distinction between antiarrhythmic efficacy and antifibrillatory potential. It may not follow that the latter is simply an extension of the former.

\section{VENIRICULAR TACHYCARDLA AND SUDDEN CARDIAC DEATH}

An experimental model: Our group has made extensive use of a conscious canine model that is susceptible to the initiation of stimulus-induced ventricular arrhythmias in the subacute phase of anterior myocardial infarction. ${ }^{44,53}$ of particular interest in this model was the finding that an additional ischemic insult (initiated by a $150 \mu \mathrm{A}$ anodal current to the left circumflex coronary artery) served as a reliable model for the spontaneous onset of ventricular fibrillation. The study by Patterson et $\mathrm{al}^{44}$ also demonstrated that previous myocardial damage was a prerequisite for the observed high mortality, since dogs without anterior infarctions exhibited a low risk of ventricular fibrillation. A subsequent study ${ }^{58}$ evaluated the model further by looking at the relation between inducible ventricular tachycardia and the subsequent development of ventricular fibrillation. Results suggested that inducible arrhythmias (either sustained or nonsustained) were predictive of spontaneous ventricular fibrillation during posterolateral ischemia. The mass of previously injured myocardium was a critical determinant of both, since animals with inducible arrhythmias (24-hour mortality, 93\%) had larger infarct sizes $(24.7 \pm 1.7 \%$ of left ventricular mass) than the animals in which arrhythmias could not be induced at baseline testing (24-hour mortality, $15 \%$; infarct size, $5.3 \pm 1.1 \%$ of left ventricular mass; Table II).
Use of this canine model enabled evaluation of antiarrhythmic activity against arrhythmias thought to share the same reentrant basis as ischemic arrhythmias in humans. ${ }^{56,59}$ In addition, the model permits discrimination between antiarrhythmic activity as determined with programmed electrical stimulation versus antifibrillatory activity in the postinfarcted heart subjected to an ischemic event in a region remote from the infarct-related artery.

\section{DETERMINING ANTIFIBRILATORY ACTIVITY}

Experimental procedure: Mongrel dogs of either sex are anesthetized by the intravenous administration of sodium pentobarbital, intubated, and ventilated with room air. Using an aseptic technique, the left jugular vein is isolated and cannulated for subsequent drug administration. A left thoracotomy is performed, and the heart exposed and suspended in a pericardial cradle. The left anterior descending (LAD) coronary artery is dissected free at the tip of the left atrial appendage and the left circumflex (LCX) coronary artery isolated approximately $1 \mathrm{~cm}$ from its origin. Anterior wall infarction is achieved by a 2-hour occlusion of the LAD coronary artery followed by reperfusion in the presence of a critical stenosis. An epicardial bipolar electrode is sutured to the left atrial appendage for subsequent atrial pacing. A bipolar plunge elcctrode is sutured onto the surface of the heart in the region of the right ventricular outflow tract (RVOT) for the subsequent introduction of extrastimuli during programmed electrical stimulation. In addition, 2 bipolar plunge electrodes are sutured to the left ventricular wall; 1 in the distribution of the IAD coronary artery distal to the site of occlusion (infarct zone) and the second in the distribution of the LCX coronary artery (normal zone). Finally, a 30 -gauge electrode is inserted into the lumen of the LCX coronary artery and secured by suturing to the heart wall. Figure 2 is a schematic representation of the instrumented canine heart as used in the model of sudden cardiac death.

Programmed electrical stimulation and electrophysiologic testing are performed in the conscious, unsedated animal, 3-5 days after surgical preparation. After determination of the RVOT excitation threshold and refractory period, programmed stimulation continues with the introduction of double (S2, S3) and triple (S2, S3, S4) extrastimuli (4 msec duration at twice RVOT excitation threshold) during sinus rhythm. Previous studies indicated that these stimulation methods will not induce arrhythmias in sham-operated animals. ${ }^{44}$ 
Electrophysiologic parameters from normal and infarcted myocardium are determined from the construction of strength-interval curves using data obtained from the normal zone and infarct zone electrodes, respectively. Dogs with sustained or nonsustained ventricular tachycardia are allocated randomly to drug or vehicle groups, and electrophysiologic testing and programmed stimulation are repeated in full after drug equilibration.

On completion of the post-treatment stimulation protocol, a direct anodal current of $150 \mu \mathrm{A}$ is applied to the intimal surface of the LCX coronary artery using a $9 \mathrm{~V}$ nickel-cadmium battery and variable resistor. Application of an anodal current to the intimal surface of the vessel results in injury and exposure of the underlying collagen matrix. Platelet aggregates form on the denuded surface of the coronary artery, accompanied by cyclic variations in blood flow and a high incidence of acute ventricular fibrillation within 1 hour from the onset of ischemia as determined by depression or elevation in the ST segment of the electrocardiogram.

Lead II of the electrocardiogram is recorded at preset intervals ( $30 \mathrm{sec}$ every $15 \mathrm{~min}$ ) by a programmable cardiocassette recorder. After 24 hours of continuous application of the anodal current or the development of ventricular fibrillation, the heart is excised and any thrombus in the LCX coronary artery is removed and weighed. The heart is sectioned transversely and incubated in a $0.4 \%$ solution of triphenyltetrazolium chloride for $15 \mathrm{~min}$. Anterior and posterolateral areas of infarction are identified by their inability to reduce triphenyltetrazolium chloride enzymatically to a brick-red formazan precipitate. Infarct masses in the myocardial regions are quantified by computer-assisted planimetry and expressed as a percentage of total left ventricular mass. Playback of the cardiocassette provides information regarding the time of onset of ischemia (as assessed by the appearance of ventricular ectopy and/or ST-segment changes), the time from ischemia to death, and the percent change in heart rate before death. When last tabulated, a total of 201 inducible, vehicle-treated dogs had been studied in our laboratory; of these, $188(94 \%)$ had died within 24 hours of posterolateral ischemia in the sudden death protocol. ${ }^{60}$

The results of various pharmacologic interventions in the conscious canine model of sudden death are summarized in Table III. The data in Table III illustrate the dichotomy of action of many antiarrhythmic agents when tested both against the arrhythmias of programmed electrical stimulation and in their effects against ischemic ventricular fibrillation. Based on these observations, it could be concluded that there is little, if any, value in predicting antifibrillatory efficacy from a drug's effect on stimulus-induced ventricular tachycardia. It can be seen that clinically relevant plasma concentrations of the class IA agent quinidine were capable of preventing the induction of stimulusinduced arrhythmias, but were ineffective in preventing ventricular fibrillation ${ }^{61}$; conversely, if we ignore for the present the confounding issues with sotalol, $\beta$-adrenergic receptor blockade appears to be offering some degree of protection in the sudden death model without influencing stimulusinduced ventricular tachycardia, ${ }^{54,62-64}$ a phenomenon shared by the specific bradycardic agent alinidine.$^{65}$ Studies with 2 calcium channel antago-

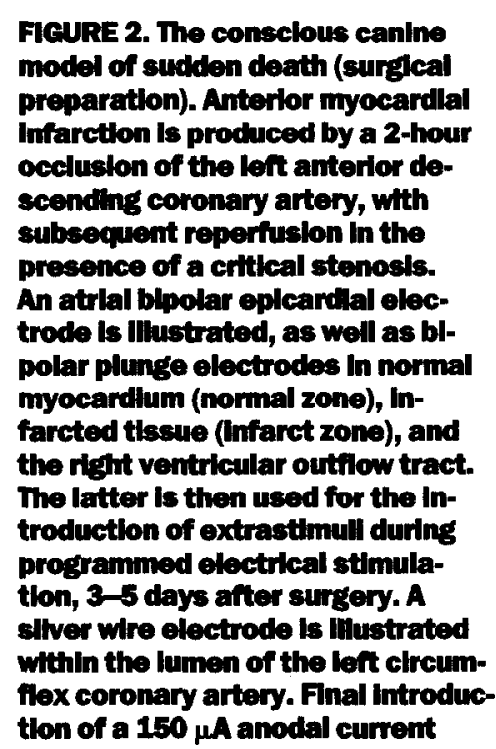

FIRUE 2. The consclous canine model of sudden death (eurjeal preparation). Anterlor myocardlal Infarction is produced by a 2-hour cceluelon of the left anterior descending coronary artery, with subeequent reperiusion in the presence of a critcal stenosis. An atrlal blpolar epleardial electrode is lliastrated, as woll as blmyocerdum (nomal zone), infarcted tisere (infarct zone), and the right ventricular outiow tract. The latter is then used for the introduction of extrastimull during prodrammed electrical stimulathon, 3-5 days after surgery. $A$ strer whe electrode is lilustrated fiex coronary artery Final lntroduc tlon of a $150 \mu \mathrm{A}$ anodal current

results in acute posterolateral lschemla and a hich Incidence of ventricular flbriliation in the sudden death protocol.

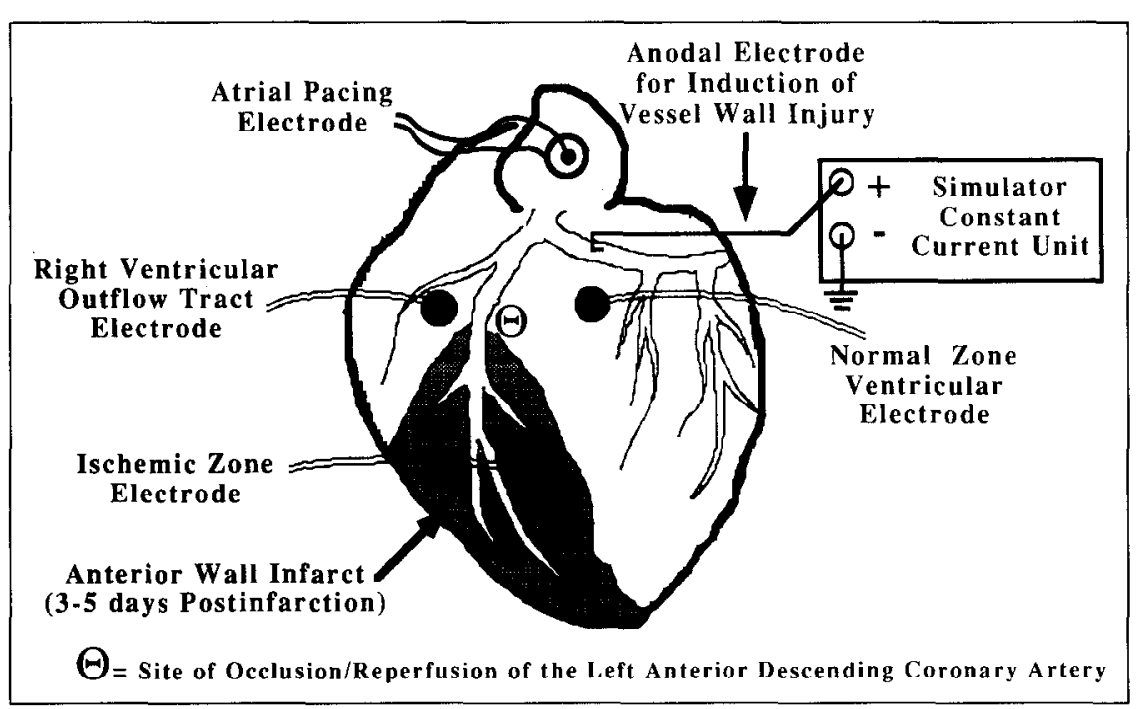




\begin{tabular}{|c|c|c|}
\hline \multicolumn{3}{|c|}{$\begin{array}{l}\text { TABLE III Drug Efficacy in the Conscious Canine Model of } \\
\text { Myocardial Infarction and Sudden Death }\end{array}$} \\
\hline Agent & $\begin{array}{c}\text { Ventricular Tachycardia } \\
\text { Suppression } \\
\text { (Programmed Stimulation) }\end{array}$ & $\begin{array}{l}\text { 24-Hour } \\
\text { Survival (\%) }\end{array}$ \\
\hline \multicolumn{2}{|l|}{ Class I } & $6^{*}$ \\
\hline Quinidine & + & 9 \\
\hline Flecainide & - & 14 \\
\hline \multicolumn{3}{|l|}{ Class II } \\
\hline Nadolol & - & $56-63$ \\
\hline Dilevalol & - & $20-60$ \\
\hline Sotalol & + & 63 \\
\hline Celiprolol & - & 30 \\
\hline \multicolumn{3}{|l|}{ Class III } \\
\hline D-Sotalol & + & 65 \\
\hline Bretylium & + & 60 \\
\hline Amiodarone & - & $40-80$ \\
\hline Clofilium & + & 30 \\
\hline CK $3579 \dagger$ & - & 70 \\
\hline Sematilide & + & 60 \\
\hline E-4031 & - & 60 \\
\hline UK 68,798 & - & 42 \\
\hline \multicolumn{3}{|l|}{ Class IV } \\
\hline Diltiazem & - & 10 \\
\hline Bepridil & + & $30-40$ \\
\hline \multicolumn{3}{|l|}{ Other } \\
\hline Alinidine & - & 60 \\
\hline Meobentine & - & 0 \\
\hline Bethanidine & - & 0 \\
\hline Prazosin & - & 50 \\
\hline CGS $12970 \ddagger$ & - & 30 \\
\hline R $68070 \$$ & - & 30 \\
\hline $\begin{array}{l}\text { *Cumulative } \\
\text { †Class Ill with } \beta_{1} \text { ad } \\
\text { fThromboxane syntl } \\
\text { \&Combined TS inhib } \\
\text { Adapted from: Lynch }\end{array}$ & $\begin{array}{l}\text { eptor antagonist properties. } \\
\text { e(TS) inhibitor. } \\
\text { id receptor antagonist. } \\
\text { Lucchesi. } .54\end{array}$ & \\
\hline
\end{tabular}

nists show bepridil to be antiarrhythmic without affecting mortality, ${ }^{66}$ whereas diltiazem did not demonstrate any beneficial effect. ${ }^{67}$ Studies with other agents not covered by the Vaughan Williams classification offer little additional insight into the antiarrhythmic or antifibrillatory relation. ${ }^{68-72}$ Even in the group with the greatest overall effect in the sudden death model, only half of the class III agents tested demonstrated a correlation with antiarrhythmic activity. Thus, it would seem reasonable to conclude that there is little prognostic value from suppression of ventricular tachycardia in this model, other than the ancillary electrophysiologic data obtained at the time of testing, which frequently provide an insight into potential antifibrillatory mechanisms.

\section{CONSCIOUS CANINE MODEL OF SUDDEN CARDIAC DEATH}

Clinical significance: A striking observation from Table III is the apparent lack of activity of the class I agents in preventing sudden death in the model. In light of what we have learned from CAST, the study with flecainide was particularly interesting in that 3 of 7 animals, noninducible at baseline and therefore at low risk from posterolateral ischemia, failed to survive the sudden death protocol. ${ }^{73}$ Thus potential profibrillatory activity with flecainide had been suggested on the basis of preclinical studies several years before CAST. The class IC agents are characterized by their ability to slow conduction velocity with only minimal effects on the duration of the refractory period of the ventricular myocardium. Flecainide in particular is of interest in that it increases the ventricular effective refractory period and, to a lesser extent, the action potential duration. On the other hand, in Purkinje fibers, action potential duration is decreased as flecainide concentration increases. ${ }^{74}$ In contrast to the actions of other antiarrhythmic agents that are sodium channel inhibitors, flecainide, like encainide, exerts a differential effect on repolarization in ventricular muscle and Purkinje fibers, an effect that is likely to aggravate heterogeneity of excitability and refractoriness on the heart and may worsen ventricular tachyarrhythmias under certain experimental or clinical situations. ${ }^{74}$ Depending on the length of the reentrant circuit, slowing of conduction velocity without a coincident lengthening of the refractory period may result in multiple reentrant circuits. ${ }^{75}$ Quinidine, as well as procainamide, 2 class IA antiarrhythmic agents, produce a prolongation of refractoriness and a rate-dependent depression of conduction velocity. The precise role of these electrophysiologic effects in mediating an antiarrhythmic action is not clear. Studies with procainamide ${ }^{76}$ indicate that lesser slowing of conduction velocity and greater prolongation of refractoriness tend to abolish reentry within the reentrant circuit. Drugs that prolong refractoriness appear more likely to be effective against tachycardia caused by reentry than are drugs that produce a slowing of conduction velocity as their major electrophysiologic effect. ${ }^{77}$

The canine model of sudden cardiac death successfully identified the proarrhythmic action of flecainide. The antiarrhythmic and antifibrillatory effects of flecainide acetate during the early postinfarction period were evaluated in the conscious canine model of sudden cardiac death. Ventricular tachycardia remained inducible early after infarction in 8 of 9 dogs receiving an intravenous loading dose of flecainide $(2.0 \mathrm{mg} / \mathrm{kg}$ body weight $)$ and 7 of 8 dogs receiving saline vehicle. In both the drug and vehicle groups, there was no significant change in the ventricular refractory period or in the cycle length of the induced ventricular tachycardia. With a maintenance intravenous infusion of flecainide, 
$1.0 \mathrm{mg} / \mathrm{kg} / \mathrm{hr}$ for 4 hours, the subsequent development of acute posterolateral ischemia resulted in ventricular fibrillation and sudden death in 7 of 8 flecainide-treated and 8 of 8 vehicle-treated dogs. Seven additional postinfarction dogs with noninducible tachycardia during pretreatment programmed stimulation, and thereby considered to be at low risk for the development of ischemic ventricular fibrillation, ${ }^{58}$ were given flecainide in an intravenous loading and maintenance dosing regimen. The subsequent occurrence of posterolateral ischemia resulted in the development of ventricular fibrillation in 3 of these 7 dogs. The findings suggest that flecainide acetate may not possess pharmacologic properties useful in managing ventricular tachycardia or in preventing ischemic ventricular fibrillation in the presence of recent myocardial damage. 73,78

The only pharmacologic intervention shown to have a beneficial effect on sudden death is $\beta$-adrencrgic receptor antagonism, where a number of studies in the postmyocardial infarction period have confirmed significant protection. ${ }^{79-83}$ In this context there also appears to be a good correlation with the conscious canine model of sudden death, since protection has been demonstrated with a number of agents. $54,63,64,84$ The antiarrhythmic and antifibrillatory potential of $\beta$-adrenoceptor antagonism, however, remains unclear; in particular, there is uncertainty over whether the drugs act by a direct antifibrillatory effect or via a primary antiischemic influence. This point is pursued in the following section.

Although no individual study with a class III agent has yet demonstrated significant antifibrillatory activity, suggestions of a beneficial trend are apparent in a recent meta-analysis. ${ }^{85}$ The authors conducted an overview of randomized controlled trials of classes I and III antiarrhythmic agents and updated earlier overviews on classes II and IV antiarrhythmic drugs. A total of 137 trials involving 96,000 patients made up the study population. It was concluded that mortality was increased significantly with class I antiarrhythmic agents, reduced with classes II and III, and not significantly altered with class IV drugs. The data suggest that amiodarone and $\beta$-adrenoceptor blocking agents are the only drugs likely to reduce mortality while other agents may be ineffective or may actually increase the likelihood of a fatal arrhythmia. With the exception of the ESVEM trial mentioned earlier, ${ }^{24}$ most of the major ongoing studies are with amiodarone, with European and Canadian postmyocardial infarction trials, and 2 placebo-controlled trials in heart failure: the Veterans Affairs Congestive Heart Failure trial of antiarrhythmic therapy and the group study of heart failure survival in Argentina (GESICA).

Pharmacologic protection: direct or indirect?

Except where ancillary electrophysiologic properties are part of a particular agent's pharmacologic profile, the $\beta$-adrenergic receptor antagonists, as a group, appear to be devoid of a direct effect on the heart. Despite this, several studies have reported significant antiarrhythmic effects with these drugs, both in clinical ${ }^{86}$ and in experimental ${ }^{87,88}$ studies. Our laboratory has examined several $\beta$-adrenoceptor blocking agents for potential antiarrhythmic and antifibrillatory activity in the canine model of sudden cardiac death. Nadolol, a noncardioselective agent, was studied in the sudden death protocol after pretreatment with $1(n=9)$ and $8(n=13)$ $\mathrm{mg} / \mathrm{kg}$. Respective survival figures were $56 \%$ and $63 \%$ ( $\mathrm{p}<0.01$ vs placebo) ${ }^{84} \mathrm{D}-\mathrm{Nadolol}$, an optical isomer devoid of $\beta$-adrenoceptor blocking properties, was ineffective. An interesting feature in this study was the observation that the majority of nadolol-treated dogs that died, did so, not from ventricular fibrillation, but as the result of complete heart block, severe bradycardia, and/or pump failure. This phenomenon was also observed in subsequent studies with dilevalol, the $R, R$-enantiomer of labetalol, where $75 \%$ of deaths were accompanied by severe bradyarrhythmias. ${ }^{54,63}$ The administration of methylscopolamine to postinfarction animals pretreated with dilevalol, however, significantly reduced mortality ( $40 \%$ vs $100 \%$ vehicle-treated; $\mathrm{p}<0.05$ ), suggesting that dilevalol, like nadolol, was capable of preventing ischemic ventricular fibrillation in this model, but that death was due to the unopposed effects of parasympathetic influences plus the inability of the sinoatrial node to manifest a positive chronotropic action due to the presence of $\beta$-adrenoceptor inhibition.

In a series of experiments with celiprolol, a class II drug with intrinsic stimulant properties, it was of significance that the drug was without effect in preventing sudden cardiac death. ${ }^{64}$ In particular, ventricular fibrillation was responsible for each of the 7 deaths in the drug-treated group. Although the model is not designed specifically to address the question of intrinsic cardiostimulant phenomena, it was noted that resting heart rate did not change after celiprolol administration, and it is possible that this feature of the drug attenuated any protection during acute posterolateral ischemia. It has been demonstrated, for example, that the propensity of sympathetic stimulation to in- 
duce arrhythmias in the late myocardial infarction period may relate primarily to heart rate. ${ }^{89}$ Previous studies have shown antagonism of the antiarrhythmic protection afforded by propranolol by overdrive atrial pacing. ${ }^{90}$ These studies also reported that $\beta$-adrenoceptor antagonists demonstrated an almost linear relation between the reduction in resting heart rate and mortality and noted that drugs with intrinsic sympathomimetic activity produced small reductions in heart rate and lesser effects on mortality. ${ }^{62}$ Although it is unclear whether celiprolol's stimulant properties are due entirely to partial agonism, ${ }^{91}$ intrinsic sympathomimetic activity is cited as a possible reason why the drug failed to exert a beneficial influence on ventricular arrhythmias in a group of patients with acute myocardial infarction. ${ }^{92}$

In an attempt to clarify the role of heart rate in the genesis of sudden death, we evaluated the antifibrillatory effects of alinidine, the $\mathrm{N}$-allyl derivative of clonidine. Alinidinc is one of a number of agents in which the main pharmacologic action appears to be a reduction in heart rate from a direct action on the sinus node. ${ }^{93,94}$ Although capable of attenuating the chronotropic response to isoproterenol, these drugs do not operate by antagonism of $\beta$-adrenoceptors. ${ }^{93,95}$ Similarly, there is no evidence that the specific bradycardic action involves $\alpha$-adrenergic or muscarinic receptors, or calcium channels. ${ }^{93,95,96}$ However, studies in isolated tissues have shown a nonvoltage-dependent decrease in the slope of the slow diastolic depolarization, indicating that the drugs' effects may be mediated by restriction of current through anionselective channels. ${ }^{96}$ In the canine model of sudden cardiac death, alinidine $(1 \mathrm{mg} / \mathrm{kg})$ produced a significant $(p<0.01)$ decrease in resting heart rate and prevented ventricular fibrillation in 6 of 10 animals studied ( $p<0.05$ vs concurrent placebo group). In a third group of dogs in which constant atrial pacing maintained heart rates at predrug values throughout the sudden death protocol, mortality was $100 \%$ despite pretreatment with alinidine ${ }^{65}$ No changes were observed on parameters of ventricular refractoriness or conduction velocity.

Bradycardic agents, such as the $\beta$-adrenoceptor antagonists, are capable of increasing perfusion pressure distal to a coronary artery stenosis, ${ }^{97}$ an effect that, for the bradycardic agents at least, appears to bc attenuated by atrial pacing to control (predrug) heart rate values. ${ }^{98}$ Thus, during posterolateral ischemia, drugs with a negative chronotropic action may contribute to an enhanced collateral flow in the ischemic bed secondary to slowing of heart rate, prolongation of diastole, and presumed reduction in myocardial oxygen consumption.

An additional property of the $\beta$-adrenoceptor antagonists is their ability to attenuate the potentially deleterious influence of enhanced adrenergic stimulation. In this respect, it is interesting to consider results in the sudden death model with the $\alpha_{1}$-adrenoceptor antagonist prazosin. Despite an inability to alter electrocardiographic intervals, ventricular refractoriness, or the induction of ventricular tachycardia by programmed stimulation, pretreatment with $500 \mu \mathrm{g} / \mathrm{kg}$ of prazosin resulted in a $50 \%$ survival rate in the sudden death protocol ( $p<0.05$ vs placebo) ${ }^{70}$ This may be of particular significance in view of the recent suggestion that $\alpha$-adrenergic responsiveness may be enhanced under conditions of myocardial ischemia ${ }^{99}$ and that this is correlated with an increase in $\alpha$-adrenoceptor concentration. ${ }^{100}$ Although the relative contributions of $\alpha$ - and $\beta$-adrenergic influences in the genesis of ventricular fibrillation remain unclear, it has been suggested that $\alpha$-mediated prolongation of action potential duration in ischemic areas may combine with $\beta$-mediated shortening of action potential duration in nonischemic areas to increase disparity in refractory periods and produce the arrhythmogenic milieu suitable for the emergence of fatal reentrant pathways. ${ }^{101}$ Antagonism of either adrenergic pathway (by the respective adrenergic antagonist) could therefore be seen as an indirect reduction in the electrophysiologic derangements leading to ventricular fibrillation and explain the protection afforded by both the $\beta$-adrenoceptor antagonists and prazosin in the animal model of sudden cardiac death.

In identifying a common direct electrophysiologic characteristic for antifibrillatory efficacy in the experimental model of sudden cardiac death, it becomes apparent that the greatest overall protection has been seen with agents that have as part of their pharmacologic profile prolongation of the action potential duration (class III activity). Studies with bretylium, ${ }^{102}$ amiodarone, ${ }^{103}$ sotalol, ${ }^{104,105}$ and a number of experimental agents ${ }^{106-108}$ have demonstrated significant protection in placebocontrolled studies. The effects of clofilium, an alternative class III drug, were less clear ${ }^{109}$ and may relate to a failure to provide an appropriate dosing regimen.

Bretylium was introduced into clinical cardiology in the early 1980s and is currently one of the few drugs marketed as an antifibrillatory agent. Its electrophysiologic properties include direct effects 
on cardiac action potential duration and indirect effects mediated via its actions on the autonomic nervous system. Early studies with the drug demonstrated suppression of stimulus-induced ventricular tachycardia ${ }^{10,111}$ and elevation in ventricular fibrillation thresholds. ${ }^{112}$ In the sudden cardiac death model, bretylium $(10 \mathrm{mg} / \mathrm{kg}$ intravenously every 6 hours) resulted in significant prolongation of ventricular refractoriness and the survival of 6 of the 10 animals studied ( $p<0.05$ vs placebo). The exact antifibrillatory mechanism of the drug, however, remains obscure; although bretylium has been shown to exert similar electrophysiologic effects in the denervated heart, ${ }^{113}$ the significance of its autonomic effects on the development of ventricular fibrillation is unknown. Further, studies with bethanidine ${ }^{68}$ and meobentine ${ }^{69}$ failed to prevent ventricular fibrillation and sudden death in the same model, despite similar structural and electrophysiologic characteristics.

Amiodarone originally was introduced as an antianginal agent, but subsequently was found to have electrophysiologic features attributable to each of the 4 classes of antiarrhythmic action. ${ }^{114-116}$ In addition, the drug reduces the inotropic and chronotropic responses of other agents and has vasodilatory effects on the coronary and systemic vasculature. ${ }^{117}$ Its outstanding property, however, is prolongation of the cardiac action potential, prompting its identification as a potential antifibrillatory agent. Despite the observation that alterations in action potential duration and ventricular refractoriness are apparent only with chronic dosing, studies in our laboratory have demonstrated significant antifibrillatory protection after both longand short-term oral therapy. Although no differences were observed in plasma or myocardial concentrations of amiodarone between the 2 dosing regimens, the greater survival in those animals treated for 10 days ( $80 \%$ vs $60 \%$ treated acutely) suggests that long-term therapy may have additional, as yet unidentified actions contributing to greater efficacy. It is known that the electrophysiologic effects of amiodarone resemble closely those of hypothyroidism ${ }^{118,119}$; that this is not due to the iodine moiety of the drug has been shown in experiments where the administration of iodine has had no effect on cardiac action potentials. ${ }^{120}$ However, the concomitant administration of amiodarone and thyroid hormone has prevented the repolarization changes seen with amiodarone alone, and thyroidectomy can protect postinfarction animals from ischemic ventricular fibrillation in the sudden death protocol. ${ }^{121}$
The effects of sotalol and its dextrorotatory enantiomer, D-sotalol, have been of particular importance in correlating the antifibrillatory potential of pharmacologic agents with their known electrophysiologic characteristics. Racemic sotalol is a noncardioselective $\beta$-adrenoceptor antagonist that produces a dose-dependent prolongation of action potential duration without associated class I (membrane-stabilizing) properties; D-sotalol, however, while retaining the same cardiac electrophysiologic profile, does not share to the same extent the parent compound's $\beta$-adrenoceptor blocking propcrties. The use of D-sotalol allows an assessment of the relative antifibrillatory action of the drug's direct electrophysiologic effects, divorced from the confounding influence of $\beta$-adrenoceptor antagonism. Initial studies with racemic sotalol demonstrated a $65 \%$ survival in animals treated with the drug and entered into the sudden death protocol. ${ }^{104}$ The protective effect was associated with significant prolongation of the QT interval (an electrocardiographic parameter of action potential duration) and bridging diastolic electrical activity of the lead II electrocardiogram, a phenomenon invariably followed by ventricular fibrillation in vehicle-treated animals. In a subsequent study with the $\mathrm{D}$ isomer, Lynch and coworkers ${ }^{105}$ demonstrated similar electrophysiologic and antifibrillatory effects, but without the attenuation of the ischemia-induced increase in heart rate seen with the parent compound. This suggested that the observed antifibrillatory effect of D-sotalol was not related to antagonism of the $\beta$-adrenoceptor, but stemmed directly from prolongation of action potential duration and the increase in the ventricular refractory period.

More recent studies from this laboratory have reinforced the positive trend seen with agents sharing the ability to prolong ventricular refractoriness. The experimental agents CK-3579 and sematilide, ${ }^{106}$ E-4031, ${ }^{107}$ and UK-68,798 ${ }^{108}$ have produced protection in placebo-controlled studies in the canine model of sudden cardiac death.

\section{CLASS III ANTIRRHMTHMIC AGENTS}

One activity, but uncertain mechanisms: The Vaughan Williams classification was the first serious effort to classify antiarrhythmic agents based on what was known regarding common electrophysiologic characteristics of the available drugs in the early $1970 \mathrm{~s} .{ }^{122}$ It is widely recognized, however, that the classification is not without major inadequacies, not least of which being that the system is essentially a hybrid: Classes I and IV represent 
agents that impair ion channels; class II agents inhibit receptors; and class III agents change an electrophysiologic variable (the action potential duration). ${ }^{123}$ Although actual mechanisms contributing to the class III effect were not known 20 years ago, the common feature now appears to be interruption of normal potassium efflux by antagonism of one or more of the potassium channels. ${ }^{124,125}$ With the increased understanding of the role of various potassium channels in health and disease has come an explosion of publications on the subject and an ever-increasing number of newly discovered channcls in various organ systems. ${ }^{126}$

\section{POTASSIUM CURRENTS THAT PREDOMINATE DURING ALTERED METABOUC STATES}

Abnormalities of membrane function arise in response to myocardial ischemia or hypoxia and favor the development of slow conduction and unidirectional block. Both conditions are essential for establishing a reentrant pathway capable of supporting ventricular tachyarrhythmias. Among the electrophysiologic changes observed in the ischemic or hypoxic tissue is the abrupt increase in extracellular potassium concentration accompanied by intracellular acidosis and a decrease in tissue adenosine triphosphate concentration. Myocardial hypoxia is associated with $\mathrm{K}^{+}$efflux from cardiac myocytes and a shortening of the action potential duration. ${ }^{127,128} \mathrm{~A}$ mechanism involving opening of $\mathrm{K}^{+}$selective channels during ischemia has been proposed to account for ischemiainduced myocyte $\mathrm{K}^{+}$loss. In addition, conditions of metabolic inhibition, as with ischemia or hypoxia, lead to the liberation of free fatty acids and a gain in intracellular sodium and calcium ions. The decrease in tissue adenosine triphosphate content, the increase in tissue free fatty acids, and the gain in intracellular sodium and calcium ions, each activate separate potassium channels. The singlechannel conductance of the $\mathrm{K}^{+}$channels activated under pathophysiologic conditions is greater than that occurring when $\mathrm{K}^{+}$channels are operative under normal conditions. Conditions of altered myocardial metabolism resulting from hypoxia and/or ischemia would favor outward rectification, so that the outward current predominates over the inward current. Significant outward current would flow during depolarization, resulting in a decrease in the action potential duration. The accumulation of $\mathrm{K}^{+}$in the extracellular space will depolarize the myocardial cell membrane. The net result of the local ionic events is to decrease conduction velocity and shorten the effective refractory period, which in the presence of a suitable myocardial substrate has the potential to result in a lethal arrhythmia. The $3 \mathrm{~K}^{+}$channels that predominate under pathophysiologic conditions may act synergistically to favor outward rectification and provide the conditions needed for reentry. The most widely studied of the 3 pathophysiologic channels in the heart is the adenosine triphosphate-dependent potassium channel $\left(\mathrm{K}_{\mathrm{ATP}}\right)$.

With the discovery of a $\mathrm{K}_{\mathrm{ATP}}$ channel regulating insulin release in the pancreatic islet $\beta$ cells, ${ }^{129}$ and its subsequent determination in the heart, ${ }^{130}$ came the realization of a cardiac channel active only in pathologic (hypoxic or ischemic) circumstances, where it could potentially play a crucial role in the genesis of fatal reentrant arrhythmias. Further, the functional or active $K_{A T P}$ channels would become manifest only in myocardial cells in which intracellular adenosinc triphosphatc was decreased. The concept was supported by the finding that glyburide, a sulfonylurea that (like all members of its class) exerted an antidiabetic effect by promoting the closure of pancreatic $K_{A T P}$ channels, could also reverse the electrophysiologic consequences of ischemia in isolated myocardial cells. ${ }^{131}$ At about the same time, independent research had demonstrated that glyburide was effective in preventing the development of ventricular fibrillation in isolated heart preparations under conditions of low intracellular adenosine triphosphate, whether the result of ischemia ${ }^{132,133}$ or hypoxia. ${ }^{134}$ When hearts are made hypoxic or ischemic in the presence of glyburide, the potassium loss during the early phase is partially blocked by the glyburide. ${ }^{135-137}$ Based on these observations, it appears that part of the potassium loss during hypoxia or ischemia can be attributed to activation of the $\mathrm{K}_{\mathrm{ATP}}$ channel, although other mechanisms may be involved, such as the $\mathrm{Na}^{+}$-activated and fatty acid sensitive $\mathrm{K}^{+}$ channels. Thus, arachidonic acid and its metabolites, as well as other unsaturated fatty acids, can modulate $\mathrm{K}^{+}$channel activity. Understanding the manner in which pharmacologic interventions modulate the several potassium channels in the ventricular myocardium is complicated by the fact that there seems to be an interaction among the activity of potassium-channel modulators and tissuc metabolites. For cxample, the effectivencss of glyburide to block the $K_{\mathrm{ATP}}$ channel depends on the cytosolic concentration of adenosine diphosphate, ${ }^{138}$ whereas the ability of pinacidil to act as an opener depends on the cytosolic content of adenosine triphosphate. ${ }^{139,140}$ There is no doubt that the tissue content of both adenosine triphos- 
phate and adenosine diphosphate will be altered during intervals of hypoxia and ischemia as well as on reperfusion. Thus, alterations in tissue metabolites will influence the final outcome of any experimental protocol and may account for incongruous results among laboratories, because the content of tissue metabolites may vary according to the particular experimental protocol employed.

Our laboratory has confirmed the antifibrillatory effect glyburide in the rabbit isolated heart made hypoxic in the presence of pinacidil ${ }^{141}$ (Figure 3). Pinacidil promotes intracellular potassium efflux and significantly reduces action potential duration via an agonist effect on $K_{\text {ATP }}$ channels. ${ }^{139,142}$ In the normoxic heart under atrial pacing, pinacidil is without discernible effects on cardiac rhythm, despite the fact that a significant decrease in ventricular effective refractory period occurs, presumably due to opening of the $\mathrm{K}_{\mathrm{ATP}}$ channel. However, in the presence of pinacidil, but less likely in its absence, ventricular fibrillation occurs in $>80 \%$ of hearts made hypoxic for 12 minutes or occurs shortly after the heart is reoxygenated. ${ }^{141}$ The induction of ventricular fibrillation in the presence of pinacidil is dependent on a decrease in myocardial cell adenosine triphosphate content (Figures 4 and 5), thereby suggesting that the myocardial $K_{\mathrm{ATP}}$ channel shows increased responsiveness to the agonist effects of pinacidil when it is disinhibited as a result of decreased cellular adenosine triphosphate. Glyburide, known for its ability to inhibit the $\mathrm{K}_{\mathrm{ATP}}$ channel, prevents the pinacidil-induced decrease in the effective refractory period and significantly reduces the incidence of ventricular fibrillation in the hypoxic/ reoxygenated perfused heart. ${ }^{141}$ The profibrillatory action of pinacidil is unmasked by myocardial hypoxia or ischemia, either of which will decrease myocardial cell adenosine triphosphate content. It is anticipated that a lowering of myocardial adenosine triphosphate will favor opening of the $K_{A T P}$ channel, especially in the presence of the agonist pinacidil. The 2 events, lowering of cellular adenosine triphosphate and further opening of the $\mathrm{K}_{\mathrm{ATP}}$ channel by the agonist pinacidil, would favor the rapid outward movement of potassium and a marked decrease in the ventricular refractory period.

It is proposed that a special binding site is located on the intracellular side of the membrane by which adenosine triphosphate closes the $K_{\text {ATP }}$ channel. ${ }^{143}$ Opening of the $\mathrm{K}_{\mathrm{ATP}}$ channel occurs when intracellular adenosine triphosphate content is reduced. Under conditions of reduced intracellular adenosine triphosphate, pinacidil is more likely to facilitate an opening of the $\mathrm{K}_{\mathrm{ATP}}$ channel, thereby enhancing an effect similar to that of a reduced intracellular adenosine triphosphate concentration. It has been suggested that pinacidil opens the $\mathrm{K}_{\mathrm{ATP}}$ channel by antagonizing adenosine triphosphate binding or that pinacidil binds to a different site and modulates the affinity of the receptor to adenosine triphosphate by a pseudocompetitive action. ${ }^{144}$ Consistent with this explanation is the observation that only channels closed by low concentrations of adenosine triphosphate could be opened by potassium channel agonists. ${ }^{139,145}$ Therefore, the "open" probability of the $\mathrm{K}_{\mathrm{ATP}}$
FICURE 3. Schematic representation of the experimental model for perfusion of the rabbit isolated heart under conditions of varying oxygen tension. The use of a "membrane lung" allows for the rapld change in the oxygen tension of the perfusion medium. After a perlod of equilibration under normoxic perfiusion, the hearts are subjected to $12 \mathrm{mln}$ utes of hypoxia and then reoxygenated for $\mathbf{4 0}$ minutes. The test drugs are added to the perfusion medum before the Induction of hypoxda. Heart rate is maintained constant by atrlal pacing and coronary perfusion is not altered throughout the study protocol. (EKE = electrocardilogram; LV = left ventricular)

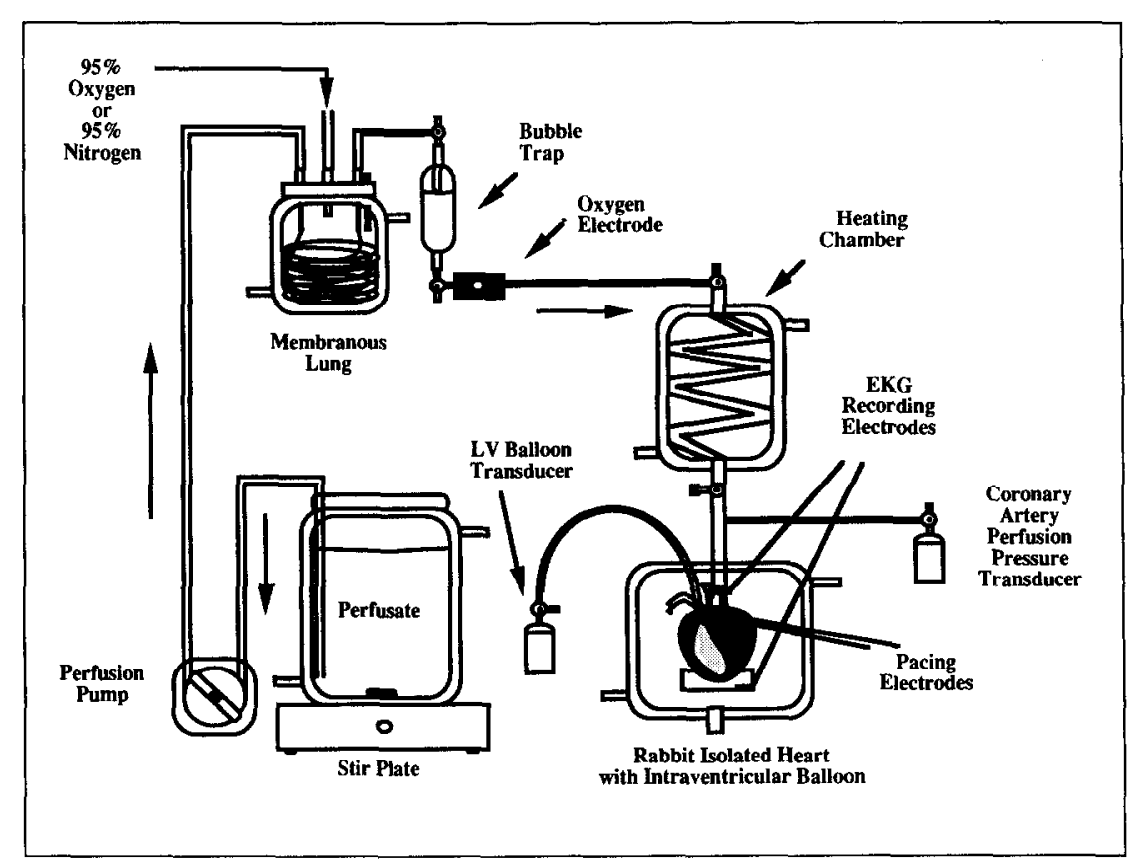


channel can be significant in the absence of adenosine triphosphate and can be influenced further by the interaction of cofactors formed during ischemia or hypoxia, as discussed above.

The possibility must be entertained that during ischemia there may be a finite probability for the channel to open. Half-maximal sensitivity of the channel increases 4-fold by the addition of adenosine diphosphate and guanosine diphosphate in concentrations known to exist during metabolic inhibition or ischemia. ${ }^{146,147}$ A significant open probability of the $\mathrm{K}_{\mathrm{ATP}}$ channel may be expected under appropriate conditions, cven with millimolar concentrations of adenosine triphosphate. ${ }^{147,148}$ The $\mathrm{K}_{\mathrm{ATP}}$ channel-dependent action potential shortening is likely to occur if adenosine triphosphate concentration falls below normal levels (approxi-

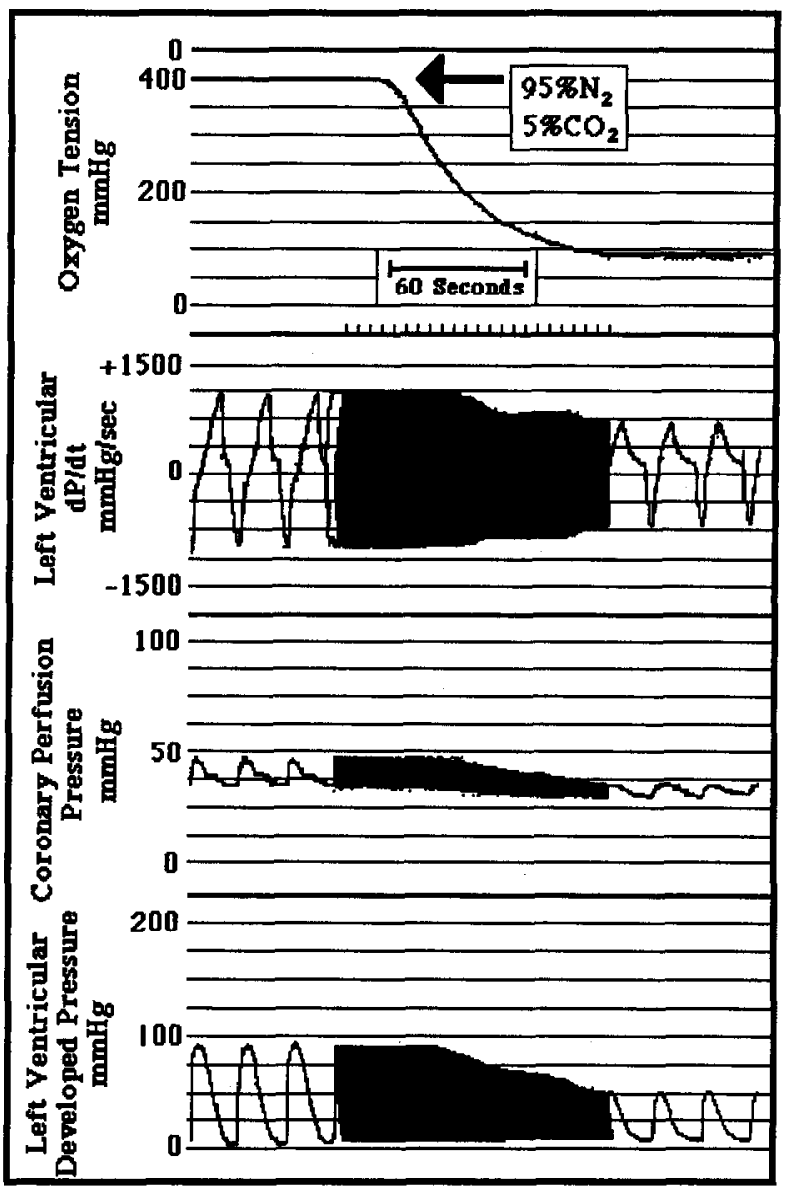

FICURE 4. Representative recording from the rabblt lsolated heart during nomoxic and hypoxlc perfusion. The tracings from above dowmward represent: oxygen tension of the perfusion medium, left ventricular $\pm d P / d t$, coronary perfusion pressure, and left ventricular developed pressure. The functlonal effects of changing the gas mixture in the artificlal lung become evident within 1 minute as manifested by a decrease in $\pm d P / d t$, coronary artery perfuslon pressure, and left ventricular developed pressure. Myocardlal tlssue content of adenosine triphosphate is reduced approximately $50 \%$ during the 12-minute exposure to hypoxic perfision. mately $5 \mathrm{mM}$ ), as may happen regionally or globally during myocardial ischemia. ${ }^{149}$ The known relation between cellular adenosine triphosphate concentration and the functioning of the $K_{\mathrm{ATP}}$ channel would suggest that selective channel agonists should be more effective in the ischemic heart than in normal myocardium. Our observations in the intact postinfarcted canine heart and in the hypoxic perfused heart would support the conclusion that $\mathrm{K}_{\mathrm{ATP}}$ channel openers, while of no deleterious consequence during normal oxygenation, become profibrillatory under conditions of metabolic inhibition leading to a decrease in intracellular adenosine triphosphate concentration. ${ }^{133,141,150,151}$

Confusion arises over whether it is more advantageous to restore an abnormally shortened action potential to a normal action potential by application of a $\mathrm{K}_{\mathrm{ATP}}$ channel closer (e.g., glyburide) or to shorten further the action potential in cardiac cells by administration of a $\mathrm{K}_{\mathrm{ATP}}$ channel opener (e.g., pinacidil). Studies designed to examine myocardial recovery of contractile function suggest the latter alternative as the more desirable course of action to prevent the deleterious effects of ischemia and preserve the viability of cardiac cells and recovery of contractile function. ${ }^{152-156}$ Future studies must address the issue of whether it is more important to preserve contractile function at the risk of jeopardizing electrophysiologic properties of the heart subjected to metabolic inhibition. Will inhibitors of the $\mathrm{K}_{\mathrm{ATP}}$ channel, other than glyburide, have the same undesirable effects on recovery of function? To date, class III antiarrhythmic agents known to inhibit the delayed rectifier current have not been

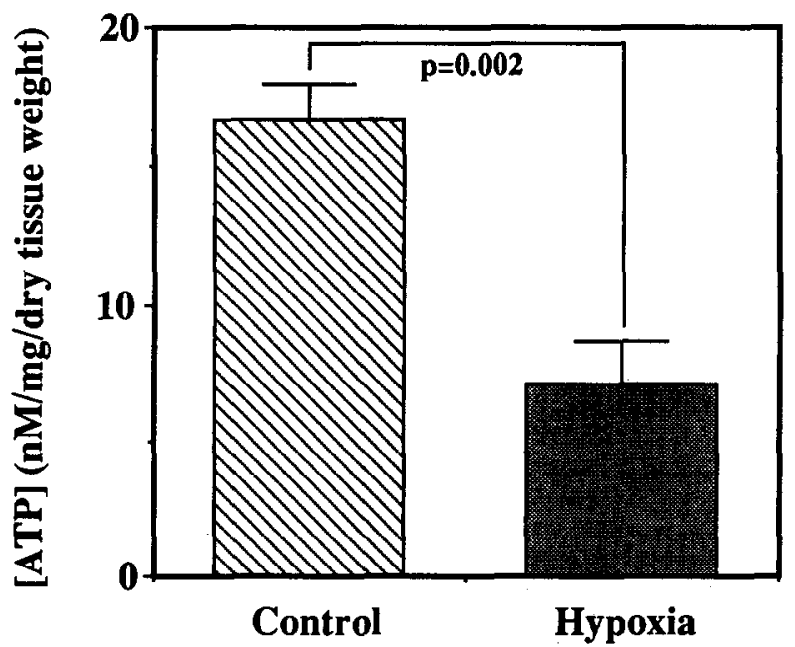

FICURE 5. Myocardlal tlssue adenosine triphosphate (ATP) content was determined in a control group of hearts perfused under nomoxic conditions and in a secend group of hearts subjected to 12 minutes of hypoxic perfusion. The reduction In tissue adenosine triphosphate content was significant when compared with the controls. 
shown to influence ischemic myocardial injury ${ }^{157}$ but in contrast may exhibit a positive inotropic action as assessed by the measurement of $d P / d t{ }^{158}$ The class III antiarrhythmic agents differ significantly from glyburide with respect to modulating the effects of ischemia on myocardial tissue, since the latter has been reported to have a negative influence on functional recovery and tissue viability after ischemic myocardial injury. ${ }^{152,159}$

Pharmacologic interventions directed at blocking the $\mathrm{K}_{\mathrm{ATP}}$ channel, thereby preventing a decrease in the ventricular refractory period, may provide a useful approach to the prevention of ventricular fibrillation, without necessarily possessing antifibrillatory activity as manifested by the reduction or prevention in premature ventricular depolarizations. Based on these observations, it is suggested that inhibition of the $\mathrm{K}_{\mathrm{ATP}}$ channel, by preventing potassium efflux, will antagonize reductions in the action potential duration and will prevent the shortening of refractoriness in ischemic and adenosine triphosphate-depleted myocardial cclls. By so doing, disparity in refractory periods can be avoided and with it the risk of emergent ventricular reentrant arrhythmias.

Using a cohort of small-infarct, noninducible dogs similar to those described above in the flecainide study, we evaluated the profibrillatory action of pinacidil in the sudden cardiac death model. Compared with a 24-hour mortality in the placebo group of $20 \%$ (incidence of ischemic ventricular fibrillation, $6.7 \%$ ), mortality in the pinacidil group was $87 \%$ (ischemic fibrillation, $60 \%$ ), a difference statistically significant at the $\mathrm{p}<0.01$ level. Changes in arterial blood pressure did not reach statistical significance, indicating that the profibrillatory effect could not be explained on the basis of hypotension. ${ }^{150}$ These studies provide further support for the pivotal role of the $\mathrm{K}_{\mathrm{ATP}}$ channel in the genesis of fatal cardiac arrhythmias. In the search for the $\mathrm{K}_{\mathrm{ATP}}$ channel antagonist to be developed as the first potential antifibrillatory agent, the hypoglycemic properties of the sulfonylureas make their evaluation particularly difficult in the intact animal. However, a number of unrelated compounds claim to have $\mathrm{K}_{\mathrm{ATP}}$-blocking activity as part of their pharmacologic profile; one in particular, 5-hydroxydecanoic acid, purports to be a "pure" $K_{\text {ATP }}$ channel antagonist and appears to attenuate ischemic ventricular fibrillation in the rat heart. ${ }^{160}$ The preliminary results with 5-hydroxydecanoic acid require further cvaluation in appropriate in vivo models.

Most of our understanding of the channel block- ing actions of class III antiarrhythmic agents is derived from voltage clamp studies. Such studies provide a clear demonstration of an hypoxiainduced increase in time-independent $\mathrm{K}^{+}$current as being the important factor in shortening of the ventricular action potential. Although the derived information is promising, there remains a void in our knowledge concerning the relation of the observed electrophysiologic and ionic changes to the onset of malignant disturbances in cardiac rhythm under conditions that approximate the clinical situation of sudden cardiac death. The use of the canine model of sudden cardiac death has proved valuable in bridging the gap between the electrophysiologic studies and events as they occur in the intact heart under pathophysiologic conditions. The isolated perfused rabbit heart subjected to hypoxia and tested with the $K_{\text {ATP }}$ channel opener, pinacidil, represents a valuable addition to the study of class III antifibrillatory agents. In this model, the induction of ventricular fibrillation is dependent on the hypoxia-induced decrease in tissuc adenosine triphosphatc content together with the influence of the $K_{\text {ATP }}$ channel opener pinacidil to facilitate the opening of the $K_{A T P}$ channel. The ability of glyburide and a number of class III antiarrhythmic agents (E-4031, 5-hydroxydecanoate) to protect against the development of ventricular fibrillation suggests a role for the $\mathrm{K}_{\mathrm{ATP}}$ channel in the development of ventricular fibrillation (Figure 6). The antifibrillatory action of these agents may be attributed, in part, to the suppression of $\mathrm{K}^{+}$release from hypoxic or ischemic myocardium, perhaps through inhibition of the adenosine triphosphate-regulated $\mathrm{K}^{+}$channel. We believe that it is the tissue adenosine triphosphate content and not the direct effects of hypoxia or reoxygenation that influences the action of pinacidil on cardiac rhythm. The $\mathrm{K}^{+}$channel putatively responsible for ischemia or hypoxia-induced $\mathrm{K}^{+}$ loss is the adenosine triphosphate-dependent $\mathrm{K}^{+}$ channel present in cardiac cells. ${ }^{130}$ Under normoxic conditions, the adenosine triphosphate-dependent $\mathrm{K}^{+}$channel is blocked by high intracellular adenosine triphosphate concentrations. Depletion of cellular adenosine triphosphate (as can occur during hypoxia, ischemia, or in the presence of a metabolic inhibitor) disinhibits the blockade of the channel and allows for $\mathrm{K}^{+}$efflux to occur. A role for the adenosine triphosphate-dependent $\mathrm{K}^{+}$channel in hypoxia/ischemia-induced $\mathrm{K}^{+}$loss has been shown by specific inhibition with glyburide or tolbutamide. ${ }^{133,135,161}$ Glyburide inhibits both ischemia-induced myocardial $\mathrm{K}^{+}$loss and ischemia- 
induced ventricular fibrillation. The latter observation provides evidence that the $\mathrm{K}^{+}$loss resulted from opening of the adenosine triphosphatedependent $\mathrm{K}^{+}$channel and that the $\mathrm{K}^{+}$efflux was related to the onset of ventricular fibrillation. ${ }^{135}$ The results of our studies may be interpreted as suggesting that pharmacologic opening of the adenosine triphosphate-dependent $\mathrm{K}^{+}$channel during hypoxia (decrease in myocardial adenosine triphosphate) or on reoxygenation (sustained decrease in myocardial adenosine triphosphate content) makes the myocardium more susceptible to the development of ventricular fibrillation. The suggestion that under certain conditions $\mathrm{K}^{+}$channel agonists may facilitate the development of ventricular fibrillation concurs with in vivo data showing the profibrillatory action of pinacidil under conditions of regional myocardial ischemia in the presence of a previous myocardial infarction. ${ }^{150}$

In addition to demonstrating antifibrillatory activity for specific interventions, results obtained in the isolated heart have supported the observations in the intact animal in which profibrillatory events have been uncovered, as was the case with flecainide. ${ }^{73,162}$ Class I antiarrhythmic agents (quinidine, aprindine, lidocaine, and flecainide) were selected for study in the isolated heart made hypoxic and treated with pinacidil. Only quinidine prevented the pinacidil-induced ventricular fibrillation. Flecainide in the presence of hypoxia, but in the absence of pinacidil, invariably was associated with the onset of ventricular fibrillation that could be prevented by pretreatment with glyburide. ${ }^{162}$ The observations suggest that ventricular fibrillation can be provoked by the potassium channel agonist pinacidil or by flecainide, under conditions that reduce intracellular adenosine triphosphate concentration. Glyburide, a selective antagonist of the $\mathrm{K}_{\mathrm{ATP}}$ channel, prevented the profibrillatory actions of both pinacidil and flecainide.

\section{CONCLUSION}

The lack of effective and safe drugs for the prevention of lethal arrhythmias and sudden cardiac death has served to stimulate renewed interest in the area of drug development and the introduction of several new candidate agents that share a common ability to prolong ventricular refractoriness. Equally important is the recognition that most antiarrhythmic agents have been evaluated with in vitro or in vivo models that have little relevance to the clinical situation of sudden cardiac death. As the recent CAST report ${ }^{17,18}$ has emphasized, the final analysis of a drug's ultimate utility will depend on appropriate clinical testing in patients who are at risk of developing sudden and unexpected life-threatening arrhythmias, or ventricular fibrillation, or both.

We can no longer afford to employ the more expedient and less dependable approach to evaluating new agents for their ability to reduce the frequency and/or complexity of ventricular depolarizations or their ability to modify the patient's response to programmed electrical stimulation. Despite the formidable task involved in the clinical assessment of an effective therapy for the prevention of ventricular fibrillation, the challenge could be made more readily attainable by preclinical assessment of a candidate drug, based on studies conducted in relevant animal models using mean-

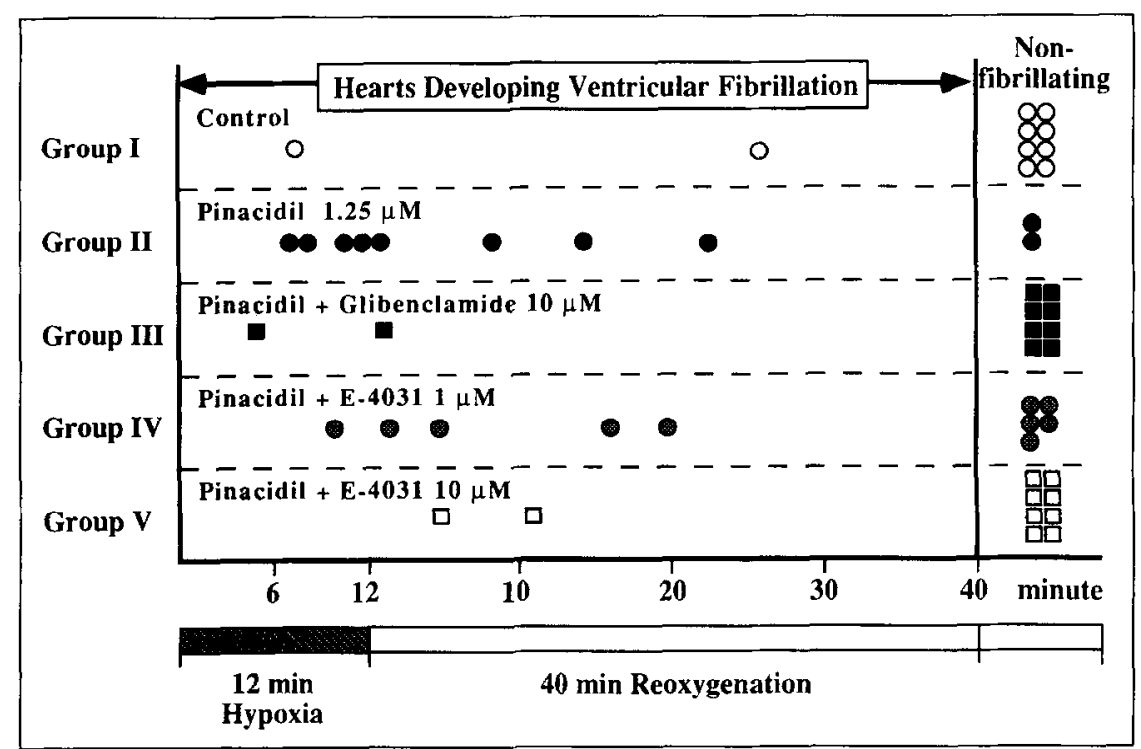

FTCURE 6. Summary of results in the lsolated heart model of hypoxla- or plnacidll-induced ventricular fibrillation. Rabbit lsolated hearts were subjected to 12 minutes of hypoxia in the absence (control) or presence of pinacldil $(125 \mu \mathrm{M})$ followed by 40 minutes of reoxysenation. Vontricular fibrillation doveloped in $20 \%$ of the control rabblts compared with $80 \%$ of the plnacidll. treated hearts. The $K_{A}$ channel blocking agent, glyburide (Albenclamide), reduced the incldence of ventricular fibriliation, as disd E-4031 The lsolated heart model may permit one to Identify antifibrillatory agents capable of Inhlbiting the $\mathrm{K}_{\mathrm{ATP}}$ channel that becomes functional in response to a decrease In myocardial adenoeline triphosphate content assoclated with the 12 minutes of hypoxic perfiuston. 
ingful electrophysiologic endpoints that occur spontaneously. To this end, we have employed an animal model of sudden cardiac death in which ventricular fibrillation develops within 1 hour from the onset of an ischemic event in a myocardial substrate that has been identified, through the use of programmed electrical stimulation, to be capable of supporting an arrhythmic mechanism. The conscious, postinfarcted, canine model has been employed by us to confirm antifibrillatory activity in a number of approved antiarrhythmic agents, proposed antifibrillatory potential in several agents at exploratory stages of development, and warn of profibrillatory dangers in others. Although a number of animal models of sudden death exist, it seems desirable to use the model with previous myocardial infarction (healed scar) and new induction of ischemia, which may most closely emulate the situation seen in the CAST. ${ }^{163}$ The animal model, together with studies conducted at the cellular, biochemical, and molecular levels, will serve as the conduits for understanding the physiopathologic events leading to lethal arrhythmias and for the development of pharmacologic interventions aimed at preventing sudden cardiac death. ${ }^{164}$

Acknowledgments: The principal investigator (B.R.L.) expresses sincere gratitude to the $\mathrm{Na}$ tional Institutes of Health, Heart, Lung, and Blood Institute for the uninterrupted support of our studies on the analysis of antiarrhythmic agents. The original studies reported from our laboratory were supported by a grant from the National Institutes of Health, Heart, Lung and Blood Institute, HL-05806-33 (Merit Award). Much of the work by the principal investigator's laboratory would not have been possible without the cooperation of colleagues in the pharmaceutical industry who provided the many drugs studicd over the past 32 years. Lastly, the principal investigator acknowledges the dedication of the many pre- and postdoctoral fellows and faculty colleagues who participated in our research program.

\section{REFERENCES}

1. Roberts WC. Sudden cardiac death: definitions and causes. Am J Cardiol 1986;57:1410-1413.

2. Kannel WB, McGee DL, Schatzkin A. An epidemiological perspective of sudden death: 26 year follow up in the Framingham Study. Dnugs 1984;28(suppl 1):1-16.

3. Myerburg RJ, Kessler K, Castellanos A. Sudden cardiac death. Structure, function, and time-dependence of risk. Circulation 1992;85(suppl):11- I10. 4. Buxton AE. Antiarrhythmic drugs: good for premature ventricular contractions but bad for patients? Ann Intem Med 1992;116:420-422.

5. Moss AJ, De Camilla J, Davis H. Factors associated with cardiac death in the posthospital phase of myocardial infarction. In: Kulbertus HE, Wellens HJJ, eds. Sudden Death. The Hague, Netherlands: Martinus Nijhoff, 1980:237247.
6. The Coronary Drug Project Research Group. Prognostic importance of premature beats following myocardial infarction. JAMA 1973;223:116-124.

7. Moss AJ. Davis HT, DeCamilla J, Bayer LW. Ventricular ectopic beats and their relation to sudden and nonsudden cardiac death after myocardial infarction. Circulation 1979;60:998-1003.

8. Hinkle LE. The immediate antecedents of sudden death. Acta Med Scand 1981;651:207-217.

9. The Multicenter Postinfarction Research Group. Risk stratification and survival after myocardial infarction. N Engl J Med 1983;309:331-336.

10. Mukharji J, Rude RE, Poole WK, Gustafson N, Thomas LJ Jr, Strauss HW, Jaffe AS, Muller JE, Roberts R, Raabe DS Jr, Croft CH, Passamani E, Braunwald E, Willerson JT, MILIS Study Group. Risk factors for sudden death after myocardiat infarction: two-year follow-up. Am J Cardiol 1984;54:3136.

11 Bigger JT, Fleiss JL, Kleiger R, Miller JP, Rolnitzky LM, Multicenter Postinfarction Research Group. The relationships among ventricular arrhyth. mias, left ventricular dysfunction, and mortality in the 2 years after myocardial infarction. Circulation 1984;69:250-280.

12. Gianelly R, von der Groeben JO, Spivack AP, Harrison DC. Effect of lidocaine on ventricular arrhythmias in patients with coronary heart disease. $N$ Engl J Med 1967;277:1215-1219.

13. Lie KI, Wellens HJ, van Capelle FJ, Durrer D. Lidocaine in the prevention of primary ventriculat fibrillation. N Engl J Med 1974;291:1324-1326.

14. Furberg $\mathrm{CD}$. Effects of antiarrhythmic drugs on mortality after myocardial infarction. Am J Cardiol 1983;52:32C-36C.

15. May GS, Furberg CD, Eberlein KA, Geraci BJ. Secondary prevention after myocardial infarction: a review of short-term acute phase trials. Prog Cardiovasc Dis 1983;25:335-359.

16. The CAPS Investigators. The Cardiac Arrhythmia Pilot Study. Am J Cardiol 1986;57:91-95.

17. CAST Investigators. Preliminary report: effect of encainide and flecainide on mortality in a randomized trial of arrhythmia suppression after myocardial infarction. N Engl J Med 1989;321:406-412.

18. CAST II Investigators. Effect of the antiarrhythmic agent morizicine on survival after myocardial infarction. $N$ Engl J Med 1992;327:227-233.

19. Wellens HJ, Schuilenburg RM, Durrer D. Electrical stimulation of the heart in patients with ventricular tachycardia. Cinculation 1972;46:216-226.

20. Roy D, Waxman HL, Kienzle MG, Buxton AE, Marchlinski FE, Josephson ME. Clinical characteristics and long-term follow-up in 119 survivors of cardiac arrest: relation to inducibility at clcctrophysiologic testing. Am J Cardiol 1983;52:969-974.

21. Ruskin JN. Role of invasive electrophysiological testing in the evaluation and treatment of patients at high risk for sudden cardiac death. Circulation 1992;85(suppl):I152-I159.

22. Skale BT, Miles WM, Heger JJ, Zipes DP, Prystowsky EN. Survivors of cardiac arrest: prevention of recurrence by drug therapy as predictied by electrophysiologic testing or ECG monitoring. Am J Cardiol 1986;57:113-119.

23. Cupples LA, Gagnon DR, Kannel WB. Long- and short-term risk of sudden cardiac death: population at risk. Circulation 1992;85:111-118.

24. The ESVEM Investigators. The ESVEM trial: electrophysiologic study versus electrocardiographic monitoring for selection of antiarrhythmic therapy of ventricular tachyarrhythmias. Circulation 1989;79:1354-1360.

25. Kuller L, Cooper M, Perper J. Epidemiology of sudden death. Arch Intern Med 1972;129:714-719.

26. Baum RS, Alvares H, Cobb LA. Survival after resuscitation from out-ofhospital ventricular fibrillation. Circulation 1974;50:1231-1235.

27. Weaver WD, Lorch GS, Alvarcz HA, Cobb LA. Angiographic findings and prognostic indicators in patients resuscitated from sudden cardiac death. Circulation 1976;54:895-900.

28. Reichenbach DD, Moss NS, Meyer E. Pathology of the heart in sudden cardiac death. Am J Cardiol 1977;39:865-872.

29. Goldstein S, Landis R, Leighton R, Ritter G, Vasu CM, Lantis A, Serokman R. Characteristics of the resuscitated out-of-hospital cardiac arrest victim with coronary heart disease. Circulation 1981;64:977-984.

30. Schuster $\mathrm{EH}$, Bulkley $\mathrm{BH}$. Ischemia at a distant site after myocardial infarction: a cause of early postinfarction angina. Cinculation 1980;62:509-515.

31 Schwartz PJ, Stone HL. Left stellectomy in the prevention of ventricular fibrillation caused by acute myocardial ischemia in conscious dogs with anterior myocardial infarction. Circulation 1980;62:1256-1265.

32. Schwartz PJ, Billman GE, Stone HL. Autonomic mechanism in ventricular fibrillation induced by myncardial ischemia during exercise in dogs with healed myocardial infarction. An experimental preparation for sudden death. Circulation 1984;69:790-800.

33. Kabell G, Brachmann J, Scherlag BJ, Harrison L, Lazzara R. Mechanisms 
of ventricular arrhythmias in multivessel coronary disease: the effects of collateral zone ischemia. Am Heant $J$ 1984;108:447-454.

34. Previtali M, Klersy C, Salemo JA, Chimient M, Panciroli C, Marangmi E, Specchia G, Comolli M, Bobba P. Ventricular tachyarrhythmias in Prinzmetal's variant angina: clinical significance and relation to the degree and time course of ST segment elevation. Am J Cardiol 1983;52:19-25.

35. Miller DD, Waters DD, Szlachcic J, Thereoux P. Clinical characteristics associated with sudden death in patients with variant angina. Circulation 1982;66: 588-592.

36. Saner HE, Gobel FL, Salomonowitz E, Erlien DA, Edwards JE. The disease-free wall in coronary atherosclerosis: its relation to degree of obstruction. J Am Coll Cardiol 1985;6:1096-1099.

37. Waller BF. Coronary luminal shape and the arc of disease-free wall: morphologic observations and clinical relevance. I Am Coll Cardiol 1985;6:1100 1101.

38. Vedernikov YP. Mechanisms of coronary spasm of isolated human epicardial coronary segments excised 3 to 5 hours after sudden death. $J$ Am Coll Cardiol 1985;8:42A-49A.

39. Factor SM, Cho S. Smooth muscle contraction bands in the media of coronary arteries: a postmortem marker of antemortem coronary spasm. J Am Coll Cardiol 1985;6:1329-1337.

40. Malliani A, Schwartz PJ, Zanchetti A. Neural mechanisms in lifethreatening arrhythmias. Am Heart $J$ 1980;100:705-715.

41. Schwartz PJ, La Rovere MT, Vanoli E. Autonomic nervous system and sudden cardiac death. Experimental basis and clinical observations for postmyocardial infarction risk stratification. Circulation 1992;85(suppl):177-191.

42. Schwartz PJ, Pagani M, Lombardi F, Malliani A, Brown AM. A cardiocardiac sympatho-vagal reflex in the cat. Circ Res 1973;32:215-220.

43. Myerburg RJ, Epstein K, Gaide MS, Wong SS, Castcllanos A, Gelband H, Bassett AL. Electrophysiological consequences of experimental acute ischemia superimposed upon healed myocardial infarction in cats. Am J Cardiol 1982;49. 323-330.

44. Patterson E, Holland K, Eller B, Lucchesi BR. Ventricular fibrillation resulting from ischemia at a site remote from previous myocardial infarction. A conscious canine model of sudden coronary death. Am J Cardiol 1982;50:1414 1423.

45. Garan H, McComb JM, Ruskin JN. Spontaneous and electrically induced ventricular arrhythmia during acute ischemia superimposed on 2 week old canine myocardial infarction. J Am Coll Cardiol 1988;11:603-611.

46. Maseri A, Severi S, Nes MD, L'Abbate A, Chierchia S, Marzilli M, Ballestra AM, Parodi O. "Variant" angina: one aspect of a continuous spectrum of vasospastic myocardial ischemia. Am J Cardiol 1978;42:1019-1035.

47. Davies MJ, Thomas A. Thrombosis and acute coronary artery lesions in sudden cardiac ischemic death. $N$ Engl J Med 1984;310:1137-1140.

48. Haerem JW. Mural platelet microthrombi and major acute lesions of main epicardial arteries in sudden coronary death. Atherosrlemsis 1974;19:529-541.

49. Mehta J, Mehta P. Role of platelets and prostaglandins in coronary artery disease. Am J Cardiol 1981;48:366-373.

50. Hammon $\mathbf{J W}$, Oates $\mathrm{J} \Lambda$. Interaction of platelets with the vessel wall in the pathophysiology of sudden cardiac death. Circulation 1986;73:224-226.

51. Moore EN, Spear JF. Acute animal models for the study of antiarthythmic drugs for the preveution of sudden coronary death. In: Lucchesi BR, Dingel JV, Schwartz RP Jr, eds. Clinical Pharmacology of Antiarrhythmic Therapy New York: Raven Press, 1984:31-46.

52. Michaelson EL. Animal models for the study of antiarthythmic drugs for the prevention of sudden coronary death: chronic animal models. In: Lucchesi BR, Dingell JV, Schwartz RP Jr, eds. Clinical Pharmacology of Antiarrhythmic Therapy. New York: Raven Press, 1984:47-70.

53. Lucchesi BR, Lynch JJ. Preclinical assessment of antiarrhythmic drugs. Fed Proc 1986;45:2197-2205.

54. Lynch JJ, Lucchesi BR. How are animal models best used for the study of antiarrhythmic drugs? In: Hearse DJ, Manning AS, Janse MJ, eds. LifeThreatening Arrhythmias and Infarction. New York: Raven Press, 1987:169.

56. Maling HM, Moran NC. Ventricular arrhythmias induced by sympathomimetic amines in unanesthetized dogs following coronary artery occlusion. Cir Res 1957:5:409-413.

56. El-Sherif N, Scherlag BJ, Lazzara R, Hope RR. Re-entrant ventricular arrhythmis in the late myocardial infarction period. 1. Conduction characteristics in the infarction zone. Circulation 1977;55:686-702.

57. Karagueuzian HS, Fenoglio JJ, Weiss MB, Wit AL. Protracted ventricular tachycardia induced by premature stimulation of the canine heart after coronary artery occlusion and reperfusion. Circ Res 1979;44:833-846.

58. Wilber DJ, Lynch JJ, Montgomery DG, Lucchesi BR. Postinfarction sudden death: significance of inducible ventricular tachycardia and infarct size in a conscious canine model. Am Heant J 1985;109:8-18.
59. Josephson ME, Horowitz LN, Farshidi A, Kastor JA. Recurrent sustained ventricular tachycardia. 1. Mechanisms. Cinculation 1978;57:431-440.

60. Uprichard ACG, Lucchesi BR. Antifibrillatory drugs. In: Dangman KH Miura DS, eds. Basic and Clinical Electrophysiology and Pharmacology of the Heart. New York: Marcel Dekker, 1991:723-740.

61. Patterson $E$, Lucchesi BR. Quinidine gluconate in chronic myocardial ischemic injury-Differential effects in response to programmed stimulation and acute myocardia ischemia in the dog. (Abstr.) Circulation 1983;68:III155.

62. Kjekshus J. Comments - beta blockers: Heart rate reduction-a mechanism of benefit. Eur Heart $J$ 1985;6:29-30.

63. Lynch JJ, Nelson SD, MacEwen SA, Driscoll EM, Lucchesi BR. Antifibrillatory efficacy of concomitant beta adrenergic receptor blockade with dilevalol, the R,R-isoner of labetalol, and muscarinic receptor blockade with methylscopolamine. J Pharmacol Exp Ther 1987;241:741-747.

64. Uprichard ACG, Lynch JJ, Kitzen JM, Frye JW, Lucchesi BR. Celiprolol, a $\beta_{1}$-selective adrenoceptor antagonist with intrinsic stimulant properties, does not protect against ventricular tachycardia or ventricular fibrillation in a conscious canine model of myocardial infarction and sudden death. $J$ Phamacol Exp Ther 1989;251:571-577.

65. Uprichard ACG, Chi L, Lynch JJ, Driscoll EM, Frye JW, Lucchesi BR. Alinidine protects against ischemic ventricular fibrillation in a conscious canine model: Probable anti-ischemic mode of action.J Cardiovasc Phamacol 1989;14: 475-482.

66. Lynch JJ, Montgomery DG, Ventura A, Lucchesi BR. Antiarrhythmic and electrophysiologic effects of bepridil in chronically infarcted conscious dogs. $J$ Pharmacol Exp Ther 1985;234:72-80.

67. Patterson E, Eller BT, Lucchesi BR. Effects of ditiazem upon experimental ventricular dysthythmins. I Phamacol Exp Ther 1983;225:224-233.

68. Patterson E, Amalfitano DJ, Lucchesi BR. Development of ventricular tachyarrhythmias in the conscious canine during the recovery phase of experimental ischemic injury: effect of bethanidine administration. J Cardiovasc Pharmacol 1984;6:470-475.

69. Zimmerman JM, Patterson E, Pitt B, Lucchesi BR. Antidysrhythmic actions of meobentine. Am Heart $J$ 1984; 107:1117-1124.

70. Wilber DJ, Lynch JJ, Montgomery DG, Lucchesi BR. Alpha-adrenergic influences in canine ischemic sudden death: effects of alpha ${ }_{r}$-adrenoceptor blockade with prazosin. J Cardiovasc Phamacol 1987;10:96-106.

71 Kitzen JM, Lynch JJ, Uprichard ACG, Venkatesh N, Lucchesi BR. Failure of thromboxane synthetase inhibition to protect the postinfarcted heart against the induction of ventricular tachycardia and ventricular fibrillation in a conscious canine model of sudden coronary death. Pharmacology 1988;37:171-186. 72. Kitzen JM, Chi L, U'Prichard ACG, Lucchesi BR. Effects of combined thromboxane synthetase inhibition/thromboxane receptor antagonism in two models of sudden death in the canine: limited role for thromboxane. $J$ Cardiovase Pharmacol 1990;16:68-80

73. Kou WH, Nelson SD, Lynch JJ, Montgomery DG, DiCarlo L, Lucchesi BR. Effect of flecainide acetate on prevention of electrical induction of ventricular tachycardia and occurrence of ischemic ventricular fibrillation during the early postmyocardial periods: Evaluation in a conscious canine model of sudden death. J Am Coll Cardiol 1987;9:359-365.

74. Ikeda N, Singh BN, Davis LD, Hauswirth O. Effects of flecainide on the electrophysiologic properties of isolated canine and rabbit myocardial fibers. $J$ Am Coll Cardiol 1985;5:303-310.

75. Brugada J, Boersma L, Kirchhof C, Brugada P, Havenith M, Wellens HJ, Allessie M. Double wave re-entry as a mechanism of acceleration of ventricular tachycardia. Curculation 1990;81:1633-1643.

76. Furukawa T, Rozanski JJ, Murue K, Gossellin AJ, Lister JW. Efficacy of procainamside on ventricular tachycardia: reiation to proiongation of refractoriness and slowing of conduction. Am Heart $J$ 1989;118:702-708.

77. Sasyniuk BI, McQuillan J. Mechanisms by which antiarrhythmic drugs influence induction of reentrant responses in subendocardial Purkinje network of 1-day-old infarcted canine ventricle. In: Zipes DP, Jalife J, eds. Cardiac Electrophysiology and Arrhythmias. Orlando, FL: Grune \& Stratton, 1983:389402

78. Lynch JJ, DiCarlo LA, Montgomery DG, Lucchesi BR. Effects of flecairide acetate on ventricular tachyarrhythmia and fibrillation in dogs with recent myocardial infarction. Pharmacology 1987;35:181-193.

79. Multicentre International Study. Improvement in prognosis of myocardial infarction by long-term $\beta$-adrenoceptor blockade using practolol. $\mathrm{Br} \mathrm{Med} J$ 1975:3:735-740

80. Norwegian Multicenter Study Group. Timolol-induced reduction in mortality and reinfarction in patients surviving acute myocardial infarction. $N$ Engl $J$ Med 1981;304:801-807.

81 Beta-Blocker Heart Attack Trial Research Group. A randomized trial of 
propanolol in patients with acute myocardial infarction. JAMA 1982;247:17071714.

82. Yusuf S, Peto R, Lewis J, Collins R, Sleight P. Beta blockade during and after myocardial infarction: an overview of the randomized trials. Prog Cardiovasc Dis $1985 ; 27: 335-371$.

83. The MIAMI Trial Research Group. Metoprolol in Acute Myocardial Infarction (MIAMI): a randomised placebo-controlled international trial. Eur Heart J 1985;6:199-226.

84. Patterson L, Lucchesi BR. Antifibrillatory actions of $d, l$-nadolol in a conscious canine model of sudden coronary death. $J$ Cardiovasc Pharmacol 1983;5: 737-744.

85. Teo K, Yusuf S, Furberg C. Effect of prophylactic antianhythmic drug therapy on post-myocardial infarction mortality. Eur Heart J 1993; JAMA 1993; (in press).

86. Kossi PR, Yusuf S, Ramsdale D, Furze L, Sleight P. Keduction of ventricular arrhythmias by early intravenous atenolol in suspected acute myocardial infarction. Br Med J 1983;286:506-510.

87. Echt DS, Griffin JC, Ford AJ, Knutti JW, Feldman RC, Mason JW. Nature of inducible ventricular arthythmias in a canine chronic myocardial infarction model. Am J Cardiol 1983;52:1127-1132.

88. Gang ES, Bigger JT, Uhl EW. Effects of timolol and propranolol on inducible sustained ventricular tachyarrhythmias in dogs with subacute myocardial infarction. Am J Cardiol 1984;53:275-281.

89. El-Sherif N. Re-entrant ventricular arrhythmias in the late myocardial infarction period 6. Effects of the autonomic system. Circulation 1978;58:103110.

90. Hope RR, Williams DO, El-Sherif N, Lazzara R, Scherlag BJ. The efficacy of antiarrhythmic agents during acute myocardial ischemia and the role of heart rate. Cinculation 1974;50:507 514

91. Wolf PS, Smith RD, Khandwala A, Van Inwegen RG, Gordon RJ, Mann WS, Romano DV, Pruss TP. Celiprolol-pharmacological profile of an unconventional beta-blocker. Br J Clin Pract 1985;39(suppl):5-11.

92. Payrhuber K, Kratzer $\mathrm{H}$, Kuhn $\mathbf{P}$. Celiprolol in acute myocardial infarct. Wien Klin Wochensch 1986;98:171-174.

93. Kobinger W, Lillie C, Pichler L. N-allyl-derivative of clonidine, a substance with specific bradycardic action at a cardiac site. Naunyn Schmiedebergs Arch Pharmacol 1979;306:255-262.

94. Kobinger W, Lillie C, Pichler L. Cardiovascular actions of N-allyl-clonidine (ST 567), a substance with specific bradycardic action. Eur J Pharmacol 1979;58: $141-150$.

95. Lillie C, Kobinger W. Actions of alinidine and AQ-A 39 on rate and contractility of guinea pig atria during $\beta$-adrenoceptor stimulation. $J$ Cardiovasc Pharmacol 1983;5:1048-1051.

96. Millar JS, Vaughan Williams EM. Pacemaker selectivity: influence on rabbit atria of ionic environment and of alinidine, a possible anion antagonist. Cardiovasc Res 1981;15:335.

97. Gross GJ, Lamping KG, Warltier DC, Hardman HF. Effects of three bradycardic drugs on regional myocardial blood flow and function in areas distal to a total or partial coronary occlusion in dogs. Circulation 1984;69:391399.

98. Gross GJ, Daemmgen JW. Effect of the new specific bradycardic agent AQ-A39 (falipamil) on coronary collatcral blood flow in dogs. $J$ Cardiovasc Pharmacol 1987;10:123-127.

99. Sheridan DJ, Penkoske PA, Sobel BE, Corr PB. Alpha adrenergic contributions to dysrhythmia cardiac muscle. Br J Phamacol 1970;39:657-667.

100. Corr PB, Shayman JA, Kramer JB, Kipnis RJ. Increased alphaadrenergic receptors in ischemic cat myocardium. J Clin Invest 1981;67:1232 1236.

101. Vaughan Williams EM. Cardiac electrophysiological effects of selective adrenoceptor stimulation and their possible roles in arrhythmias. $J$ Cardiovasc Phamacol 1985;7:S61-S64.

102. Holland K, Patterson E, Lucchesi BR. Prevention of ventricular fibrillation by bretylium in a conscious canine model of sudden coronary death. $\mathrm{Am}$ Heart J 1983;105:711-721.

103. Patterson E, Eller BT, Abrams GD, Vasiliades J, Lucchesi BR. Ventricular fibrillation in a conscious canine preparation of sudden coronary deathprevention by short- and long-term amiodarone administration. Circulation $1983 ; 68: 857-864$.

104. Patterson $E$, Lynch JJ, Lucchesi BR. Antiarrhythmic and antifibrillatory actions of the beta adrenergic receptor antagonist, $d, l$-sotalol. $J$ Pharmacol Exp Ther 1984;230:519-526.

105. Lynch JJ, Coskey LA, Montgomery DG, Lucchesi BR. Prevention of ventricular fibrillation by dextrorotatory sotalol in a conscious canine model of sudden coronary death. Am Heart J 1985;109:949-958.

106. Chi L, Mu D.X. Driscoll EM, Lucchesi BR. Antiarrhythmic and electro- physiologic actions of CK-3579 and sematilide in a conscious canine model of sudden coronary death. J Cardiovasc Pharmacol 1990;16:312-324.

107. Chi L, Mu D-X, Lucchesi BR. Electrophysiology and antiarrhythmic actions of E-4031 in the experimental animal model of sudden coronary death $J$ Cardiovasc Pharmacol 1991;17:285-295.

108. Black SC, Chi L, Mu D-X, Lucchesi BR. The antifibrillatory actions of UK-68,798, a Class III antiarrhythmic agent. J Phamacol Exp Ther 1991;258:416422 .

109. Kopia GA, Lller BT, Patterson E, Shea MJ, Lucchesi BR. Antiarrhythmic and electrophysiologic actions of clofilium in experimental canine models. Eur J Phamacol 1985;116:49-61

110. Patterson E, Gibson JK, Lucchesi BR. Postmyocardial infarction reentrant ventricular arrhythmias in conscious dogs: suppression by bretylium tosvlate. I Phamacol Exp Ther 1981;216:453-458.

111. Yatterson $\mathrm{E}$, Gibson $\mathrm{JK}$, Lucchesi BK. Prevention of chronic canine ventricular arrhythmias with bretylium tosylate. Circulation 1981;64:1045-1050.

112. Anderson JL, Patterson E, Conlon M, Pasyk S, Pitt B, Lucchesi BR. Kinetics of antifibrillatory effects of bretylium: correlation with myocardial drug concentrations. Am J Cardiol 1980;46:583-592.

113. Namm DH, Wang CM, El-Sayad S, Copp FC, Maxwell RA. Effects of bretylium on rat cardiac muscle: the electrophysiological effect and its uptake and binding in normal and immunosym-pathectomized rat hearts. $J$ Phamacol Exp Ther 1975;193:194-208.

114. Bexton RS, Camm AJ. Drugs with a class III antiarrhythmic action. 1. Amiodarone. Phamacol Ther 1982;17:315-355.

115. Gloor HO, Urthaler $F$, James TN. Acute effects of amiodarone upon the canine sinus node and atrioventricular junctional region. $J$ Clin Invest 1983;71: $1457-1466$.

116. Mason JW, Hondeghem LM, Katzung BG. Block of inactivated sodium channels and of depolarization-induced automaticity in guinea pig papillary muscle by amiodarone. Circ Res 1984;55:277-285.

117. Clatlier $R$. Cardiac actions in the dog of a new antagunist of adrenergic excitation which does not produce competitive blockade of adrenoceptors. $\mathrm{Br} J$ Pharmacol 1970;39:668-674.

118. Freedberg AS, Papp JG, Vaughan Williams EM. The effect of altered thyroid state on atrial intracellular potentials. $J$ Physiol (Lond) 1970;207:357369.

119. Johnson PN, Freedberg AS, Marshall JM. Action of thyroid hormone on the transmembrane potentials from sinoatrial node cells and atrial muscle cells in isolated atria of rabbits. Cardiology 1973;58:273-289.

120. Singh BN, Vaughan Williams EM. The effects of amiodarone, a new anti-anginal drug, on cardiac muscle. Br J Phamacol 1970;39:657-667.

121 Venkatesh N, Lynch JJ, Uprichard ACG, Kitzen JM, Singh BN, Lucchesi BR. Hypothyroidism renders protection against lethal ventricular arrhythmias in a conscious canine model of sudden death. $J$ Cardiovasc Pharmacol 1991;18: $703-711$.

122. Vaughan Williams EM. Classification of antidysrhythmic drugs. Phamacol Ther 1975;1:115-138.

123. Task Force of the Working Group on Arrhythmias of the European Society of Cardiology: The Sicilian Gambit. A new approach to the classification of antiarrhythmic drugs based on their actions on arrhythmogenic mechanisms. Circulation 1991;84:1831-1851.

124. Colatsky TJ, Follmer $\mathrm{CH} . \mathrm{K}^{+}$channel blockers and activators in cardiac arrhythmias. Cardiovasc Dnig Rev 1989;7:199-209.

125. Carmeliet E. Potassium channels in cardiac cells. Cardiovasc Dnugs Ther 1992;6:305-312.

126. Cook NS. The pharmacology of potassium channels and their therapeutic potential. Trends Pharmacol Sci 1988;9:21-28.

127. Vleugels $A$, Carmeliet $E$. Hypoxia increases potassium efflux from mammalian myocardium. Expenientia 1976;32:483-484.

128. Trautwein W, Gottstein U, Dudel J. Der Aktionsstrom der Myokardfaser im Sauerstoffmangerl. Arch Ges Physiol 1954;260:40-60.

129. Cook DL, Hales CN. Intracellular ATP directly blocks $\mathrm{K}^{+}$channels in pancreatic B-cells. Nature 1984;311:271-273.

130. Noma A. ATP-regulated $\mathrm{K}^{+}$channels in cardiac muscle. Nature $1983 ; 305$; 147-148.

131. Fosset $M$, de Weille JR, Green RD, Schmid-Antomarchi H, Lazdunski M. Antidiabetic sulfonlyureas control action potential properties in heart cells via high affinity receptors that are linked to ATP-dependent $\mathrm{K}$ channels. $J$ Biol Chem 1988;263:7933-7936.

132. Kantor PF, Coetzee WA, Dennis SC, Opie LH. Effects of glibenclamide on ischemic arrhythmias (abstr). Circulation 1987;76:IV17.

133. Wolloben CD, Sanguinetti MC, Siegl PKS. Influence of ATP-sensitive potassium channel modulators on ischemia-induced fibrillation in isolated rat hearts. I Mol Cell Cardiol 1989;21:783-788. 
134. Siegl PKS, Scott AL, Sanguinetti MC. Inhibition of anoxia- and BRL 3495-induced shortening of cardiac refractory period by the sulfonylurea, glyburide, in isolated ferret papillary muscle (abstr). J Mol Cell Cardiol 1988; 20(suppl III):S32.

135. Kantor PF, Coetzee WA, Carmeliet EE, Dennis SC, Opie LH. Reduction of ischemic $\mathrm{K}^{+}$loss and arrhythmias in rat hearts. Effect of glibenclamide, a sulfonylurea. Cir Res 1990;66:478-485.

136. Jiang $C$, Crake $T$, Poole-Wilson PA. Inhibition by barium and glibenclamide of the net loss of ${ }^{86} \mathrm{Rb}^{+}$from rabbit myocardium during hypoxia. Cardiovasc Res 1991;25:414-420.

137. Hicks MN, Cobbe SM. Effect of glibenclamide on extracellular potassium accumulation and the electrophysiological changes during myocardial ischaemia in the arterially perfused interventricular septum of rabbit. Cardiovasc Res 1991;25:407-413.

138. Venkatesh N, Lamp ST, Weiss JN. Sulfonylureas, ATP-sensitive $\mathrm{K}^{+}$ channels, and cellular $\mathrm{K}^{+}$loss during hypoxia, ischaemia, and metabolic inhibition in mammalian ventricle. Circ Res 1991;69:623-637.

139. Arena JP, Kass RS. Activation of ATP-sensitwe $K$ channels in heart cells by pinacidil: dependence on ATP. Am J Physiol 1989;257:H2092-H2096.

140. Tseng G-N, Hoffman BF. Actions of pinacidil on membrane currents in canine ventricular myocytes and their modulatin by intracellular ATP and cAMP. Pflugers Arch 1990;415:414-424.

141 Chi L, Black SB, Kou P, Fagbemi SO, Lucchesi BR. Actions of pinacidi at a reduced potassium concentration: a direct cardiac effect possibly involving the ATP-dependent potassium channel. J Cardiovasc Pharmacol 1993;21:179190.

142. Smallwood JK, Steinberg MI. Cardiac electrophysiological effects of pinacidil and related pyridylcyanoguanidines: relationship to antihypertensive activity. $J$ Cardiovasc Pharmacol 1988;12:102-109.

143. Ashcroft FM. Adenosine 5'-triphosphate-sensitive potassium channels. Annu Rev Neurasci 1988;11:97-118.

144. Fan Z, Nakayama $K$, Hiraoka M. Multiple actions of pinacidil on adenosine triphosphate-sensitive potassium channels in guinea-pig ventricular myocytes. $J$ Physiol (Lond) 1990;430:273-295.

145. Sauviat M-P, Ecault E, Faivre JF, Findlay I. Activation of ATP-sensitive $\mathrm{K}^{+}$channels by a $\mathrm{K}^{+}$channel opener (SR 44866) and the effect upon electrical and mechanical activity of frog skeletal muscle. Pflugers Arch 1991;418:261-265. 146. Nichols CG, Ledeter WJ. The regulation of ATP-sensitive $\mathrm{K}^{+}$channel activity in intact and permeabilized rat ventricular myocytes. $J$ Physiol (Lond) 1990;423:91-110.

147. Nichols CG, Lederer WJ. Adenosine triphosphate-sensitive potassium channels in the cardiovascular system. Am J Physiol 1991;261:H1675-H1686.

148. Nichols CG, Lederer WJ, Cannell MB. ATP dependence of KATP channel kinetics in isolated membrane patches from rat ventricle. Biophys $J$ 1991;60: 1164-1177.

149. Nichols CG, Ripoll C, Lederer WJ. ATP-sensitive potassium channel modulation of the guinea pig ventricular action potential and contraction. Circ Res 1991;68:280-287.

150. Chi L, Uprichard ACG, Lucchesi BR. Profibrillatory actions of pinacidil in a conscious canine model of sudden coronary death. J Cardiovasc Pharmacol 1990;15:452-464.

151 Antzelevitch C, DiDiego JM. Role of $\mathrm{K}^{+}$channel activators in cardiac electrophysiology and arrhythmias. Editorial comment. Circulation 1992;85:16271629.

152. Grover GI, McCullough JR, Henry DE, Conder ML, Sleph PG. Antiischemic effects of the potassium channel activators pinacidil and cromakalim and the reversal of these effects with the potassium channel blocker glyburide. J Pharnacol Exp Ther 1989;251:98-104.

153. Grover GJ, Dzwonczyk S, Sleph PH. Reduction of ischemic damage in isolated rat hearts by the potassium channel opener, RP 52891. Eur J Pharmacol 1990;191:11-18.

154. Auchampach JA, Maruyama $M$, Cavero $I$, Gross GJ. The new $K^{+}$channel opener Aprikalim (RP 52891) reduces experimental infarct size in dogs in the absence of hemodynamic changes. J Pharmacol Exp Ther 1991;259:961-967.

155. Auchampach JA, Maruyama M, Cavero I, Gross GJ. Pharmacological evidence for a role of ATP-dependent potassium channels in myocardiai stunning. Circulation 1992;86:311-319.

156. Lazdunski M. Potassium channels: structure-function relationships, diversity and pharmacology. Cardiovasc Dnugs Ther 1992;6:313-319.

157. Holahan MA, Stranieri MT, Stabilito II, Lynch JJ Jr. Effect of E-4031, a class III antiarrhythmic agent, on experimental infaret size in a canine model of myocardial ischemia-reperfusion injury. J Cardiovasc Pharmacol 1992;19:892898.

158. Wallace AA, Stupienski RF III, Brookes LM, Selnick HG, Claremon $\mathrm{DA}$, Lynch $\mathrm{JJ} \mathrm{Jr}$. Cardiac electrophysiologic and inotropic actions of new and potent methanesulfonanilide Class III antiarrhythmic agents in anesthetized dogs. J Cardiovasc Phamacol 1991;18:687-695.

159. Gross GJ, Auchampach JA. Blockade of ATP-sensitive potassium channels prevents myocardial preconditioning in dogs. Circ Res 1992;70:223-233.

160. Niho $T$, Notsu $T$, Ishikawa $H$, Funato $H$, Yamazaki $M$, Takahashi $H$, Tanaka I, Kayamoto M, Dabasaki T, Yamasaki F, et al. Study of mechanism and effect of sodium 5-hydroxydecanoate on experimental ischemic ventricular arrhythmia. Nippon Yakunigaku Zasshi 1987;89:155-167. (In Japanese.)

161. Gasser RNA, Vaughn-Jones RD. Mechanism of potassium efflux and action potential shortening during ischemia in isolated mammalian cardiac muscle. J Physiol (Lond) 1990;431:713-741.

162. Fagbcmi SO, Chi L, Lucchesi BR. Antifibrillatory and profibrillatory actions of selected Class I antiarthythmic agents. J Cardiovasc Pharmacol 1993; 21:709-719.

163. Pratt CM. FDA guidelines for anliarthythmic drug development. Choices Cardiol 1991;5(suppl 1):44-47.

164. Robertson DW, Steinberg MI. Potassium channel modulators: scientific applications and their therapeutic promise. J Med Chem 1990;33:1529-1541. 